Author's post-print: Carlos Slebi-Acevedo, Pablo Lastra-González, Pablo Pascual-Muñoz, Daniel Castro-Fresno. “Mechanical performance of fibers in hot mix asphalt: a review". Construction and Building Materials 200 (2019), 756-769. ISSN 09500618. DOI: 10.1016/j.conbuildmat.2018.12.171

\title{
1 Mechanical performance of fibers in hot mix asphalt: a review.
}

2 Carlos J. Slebi-Acevedo ${ }^{a}$, Pedro Lastra-González ${ }^{a}$, Pablo Pascual-Muñoz ${ }^{a}$ and Daniel 3 Castro-Fresno ${ }^{\text {* }}$

4 a GITECO Research Group, Universidad de Cantabria. Avda. de Los Castros s/n., 39005

5 Santander, Spain.

Carlos J. Slebi-Acevedo Pedro Lastra-González Pablo Pascual-Muñoz Daniel Castro-Fresno carlosjose.slebi@unican.es pedro.lastragonzalez@unican.es pablo.pascual@unican.es castrod@unican.es*

* Corresponding author: Daniel Castro Fresno

Email: castrod@unican.es

Tel.: +34942203943

Fax: +34 942201703

\section{Abstract}

The use of fibers in hot mix asphalt (HMA) has become a much more attractive alternative for the construction of road pavements. Numerous studies have shown that the incorporation of fibers in the mixture improves fatigue resistance, permanent deformation and stiffness. The aim of this paper is to present a review of the mechanical impact of fibers in HMA by analyzing their reinforcement effect in a qualitative and quantitative manner. Fiber properties and characterization tests on fiber-modified bitumen are discussed. Quantities, blending procedures and performance of bituminous mixtures with different types of fibers are presented. Results of mechanical improvement are displayed. Based on the current research results, depending on the properties and the type of mixture in which they are used, each type of fiber seems to improve certain parameters more than others. Coconut fibers and waste fibers are described as environmentally friendly alternatives.

Keywords: Fiber, hot mix asphalt, asphalt binder, mechanical properties.

\section{Highlights:}

- Mechanical characterization of fibers is described
- Papers about fiber-reinforced HMA were reviewed.

- Fibers improve the mechanical performance of hot mix asphalts.

Fibers reinforce HMA through a three-dimensional network and by increasing the adhesion in the mix.

\section{Introduction}

Scientists and engineers are permanently trying to improve properties of asphalt mixtures, such as their stability and durability, by incorporating new additives either in the bitumen or in the 
Author's post-print: Carlos Slebi-Acevedo, Pablo Lastra-González, Pablo Pascual-Muñoz, Daniel Castro-Fresno. “Mechanical performance of fibers in hot mix asphalt: a review". Construction and Building Materials 200 (2019), 756-769. ISSN 09500618. DOI: 10.1016/j.conbuildmat.2018.12.171

asphalt mixture [1-3]. Adding fibers to the binder or the bituminous mixtures ensures their stability and mechanical strength [4]. An appropriate quantity of fibers changes the properties of the asphalt, reducing the penetration and increasing the softening point. It changes the viscoelasticity of the bitumen as well [5]. Moreover, it has been shown that adding fibers to asphalt concrete increases its dynamic modulus, reinforces the mastic and reduces its thermal susceptibility, also enhancing its material strength, fatigue behavior and ductility [6,7]. Furthermore, it has been observed that fibers reduce the binder drainage and enhance moisture sensitivity and compressive strength in SMA mixtures [8-10]. Additionally, in porous asphalt mixtures some investigations have shown that fibers reduce drain down problems $[11,12]$.

Due to the extensive use of asphalt concrete for the construction of flexible pavements and its bearing comfort, this material has become essential for road engineers [13,14]. In addition to the high growth of construction and traffic flows, the consumption of bituminous material has become inevitable. Regarding this, there is a wide range of requirements in the components of mixtures necessary to obtain an asphalt mixture of high durability and performance.

Different types of fibers have been used in asphalt binders and HMA as an alternative to solve mainly mechanical performance problems. Investigations on the use of these fibers in asphalt concrete date back to 1950; nonetheless, they have already been evaluated as part of Portland cement concrete [13]. Fibers have provided this material with higher modulus, resistance, durability and deformation capacity, and hence with more ductile behavior [14]. In addition, fibers have been used as reinforcement of polymer matrices to be used in other industries $[15,16]$. These fibers endow the composites with stiffness and strength, thus enabling the matrix to better transmit the loads between fibers. Likewise, the inclusion of fibers in asphalt improves the mix properties and contributes to sustainability by extending its service life and reducing road maintenance.

There is a large number of fiber-modified asphalt binders and fiber-modified asphalt mixtures in which fibers have been used to deal with the main flexible pavement problems, such as rutting, fatigue cracking, thermal cracking and raveling [17]. Asbestos, lignite, polyester, polyacrylonitrile, carbon and brucite fibers improve the viscoelastic properties in asphalt binders [4,18-20]; meanwhile, the use of cellulose and hybrid fibers in asphalt concrete and porous asphalt mixtures leads to an increase in the tensile strength and resistance to rutting. Furthermore, a reduction of binder drain down is exhibited [21-23]. The use of glass, aramid, steel and waste fibers in asphalt concrete (AC) and stone matrix asphalt (SMA) was also investigated [24-27]. Values of resilient modulus and rutting resistance are higher in glass fiber reinforced SMA mixtures [28] while using carbon fibers leads to an increase in the Marshall stability in asphalt concretes [13]. Besides, blending procedure has an incidence in the performance of the mixtures [20].

The objective of this review is to discuss the role of fibers in bituminous binders and asphalt mixtures; consequently, physical and microstructural characterization of fibers is presented. The use of different types of fibers in the bitumen is examined based on the results of the more usual characterization tests for this type of modified binders, as well as the behavior of the fibers at high, medium and low temperatures. The drain down test is considered. As for the use of fibers in asphalt mixtures, mixing procedures are considered and further evaluated. Finally, the effect of various types of fibers on the mechanical performance of asphalt mixtures is discussed. The use of waste fibers yielded very satisfactory results, so it can provide an environmently alternative. 
Author's post-print: Carlos Slebi-Acevedo, Pablo Lastra-González, Pablo Pascual-Muñoz, Daniel Castro-Fresno. “Mechanical performance of fibers in hot mix asphalt: a review". Construction and Building Materials 200 (2019), 756-769. ISSN 09500618. DOI: 10.1016/j.conbuildmat.2018.12.171

\section{Mechanical characterization of fibers}

Fibers are a natural or synthetic material that is used in the manufacture of materials such as textiles or paper, and impregnated in materials such as cement and asphalt mixtures. Fibers in HMA act as a reinforcement. Fibrous reinforcement plays a role in ensuring strength, thermal stability, electrical conductivity and frictional properties of composites [29].

Fibers are usually classified according to their origin as organic or mineral fibers. Among organic fibers are those of cellulose and lignite, used in the manufacture of paper and textiles. Absorption and drainage are among their general properties [30,31]. On the other hand, mineral fibers include asbestos that refers to a group of silicate minerals. Asbestos fibers are soft and flexible yet resistant to heat, electricity and chemical corrosion. They can also be mixed with cement, paper, textiles and other materials to make them stronger [29]. Moreoever, there are semi-metallic fibers, also known as resin-bonded fibers, which contain $50 \%$ metal powder. Additionally, man-made fibers, non-asbestos fibers and semi synthetic fibers have been developed since 1983, which are made from raw materials and modified by chemical processes (e.g., Rayon, regenerated from natural cellulose) [32]. As for synthetic fibers, they come from petrochemicals like polymers. The most common synthetic fibers are: nylon (polyamide), polyester, polyurethane and aromatic polyamides (aramids) [33]. Finally, certain fibers are made from specific materials: fiberglass (from glass), carbon fiber (from carbon) and metal fibers (from nickel, aluminum, iron or copper). Table 1 presents a brief description of the different types of fibers used in HMA referring to the raw material in the manufacturing process.

Engineers are constantly combatting major problems in roads, including permanent deformation, fatigue cracking and raveling. For this, the most frequently added materials are polymers, anti-stripping agents, crumb rubber, sulfur, asbestos, roofing shingles, slag and fly ash, among others [34]. Inclusion of fibers in the asphalt mixtures is gathering strength as they act as a reinforcement, adding ductility and tensile strength to the material due to the enhanced interlocking of aggregates. The interconnection between aggregates and fibers enables the material to withstand additional strain energy before cracking occurs; thereby, it is of great significance for extending the useful life of safer roads $[28,35]$. 
Author's post-print: Carlos Slebi-Acevedo, Pablo Lastra-González, Pablo Pascual-Muñoz, Daniel Castro-Fresno. “Mechanical performance of fibers in hot mix asphalt: a review". Construction and Building Materials 200 (2019), 756-769. ISSN 09500618. DOI: 10.1016/j.conbuildmat.2018.12.171

\begin{tabular}{ll} 
Fiber type & Remarks \\
\hline Mineral & $\begin{array}{l}\text { Asbestos, basalt and brucite are considered the most popular group of mineral fibers. They come from deep } \\
\text { in the Earth's crust and can be found in cracks in solid rock. The most commonly used raw materials are } \\
\text { silicates [36], which can be manufactured by electro thermal methods [37,38]. }\end{array}$ \\
& $\begin{array}{l}\text { Polyester fibers, manufactured from the polymerization of ethylene, are one of the most widely used } \\
\text { synthetic fibers in the textile sector [39]. Polyester is a thermoplastic polymer which can be remelted and } \\
\text { remolded. Therefore, it is considered an easily recyclable material. Its structure is a combination of crystalline } \\
\text { and noncrystalline regions [40]. }\end{array}$ \\
Polyacrylonitrile & $\begin{array}{l}\text { Polyacrylonitrile fibers or PAN fibers as they are commonly known, are the result of the acrylonitrile } \\
\text { polymerization process in the presence of a catalyst peroxide [41,42]. Its use is linked to composite structures } \\
\text { (PAN) }\end{array}$
\end{tabular}

PAN fibers are considered the first precursor of the carbon fibers [44]. Carbon fibers exhibit higher specific strength, fatigue resistance and stiffness than any other type of reinforcement fibers. However, they have other interesting properties such as good electrical and thermal conductivity [45-47].

Carbon

Glass fiber, also called fiberglass, is considered a mineral fiber as its manufacturing process involves
limestone, kaolin clay, fluorspar, dolomite and other minerals [48].
Steel fibers are short discontinuous strips of manufactured steel. Their manufacturing process includes
different types of arrangements including the use of materials such as carbon and phosphorous [49]. Aramid fibers are considered man made high performance fibers. Aramid fiber's first commercial applications
appeared in the early 1960s and its main application is reinforcement of composites. Continuous fiber
reinforcement polymers (CFRP) or aramid fiber reinforcement polymers (ARFP) are used in sports goods,
aircraft, ballistic protection or structural applications, among others [50,51]. aircraft, ballistic protection or structural applications, among others [50,51].

\subsection{Characterization tests}

This $100 \%$ natural product is obtained from the outer shell of the coconut fruit. Their walls are composed by Coconut lignin, a complex woody chemical [52].

\subsubsection{Physical tests}

111 Good results have been obtained from the incorporation of fibers in asphalt mixtures; nonetheless, it is important to understand the fibers reinforcing mechanism. Proper interpretation of the physical properties of fibers and their microstructure makes it easier to select the most convenient type of fiber for the design of asphalt mixtures. 
Author's post-print: Carlos Slebi-Acevedo, Pablo Lastra-González, Pablo Pascual-Muñoz, Daniel Castro-Fresno. “Mechanical performance of fibers in hot mix asphalt: a review". Construction and Building Materials 200 (2019), 756-769. ISSN 09500618. DOI: 10.1016/j.conbuildmat.2018.12.171

The most interesting physical properties for further evaluation are tensile strength, modulus of elasticity, specific gravity and Mohs hardness, as shown in Table 2. These characteristics are commonly provided by manufacturers. However, as fibers can decompose while manufacturing the reinforced HMA, making their properties worse, there are two other important characteristics to consider: water susceptibility and degradation by warming. There is no regulation for tests applied to fibers; however, some authors have proposed their own methodologies. Chen and Xu [2] proposed a test to measure the water absorption in fibers, which consists of weighing a 10-gram mass of fiber and placing it in a curing chamber at $20^{\circ} \mathrm{C}$ and $90 \% \mathrm{RH}$. Then, the weight of the fibers is measured every five hours for three days, and a visual inspection is made of both shape and color. As for the second property, an evaluation of the thermostability of fibers in the mixture should be carried out, as the high temperatures of the blending process of asphalt concretes and porous asphalts (above $150^{\circ} \mathrm{C}$ ) can harm the fiber during the mixing process. The test proposed by Chen and $\mathrm{Xu}$ [2] consists of placing three 100 $\mathrm{g}$ samples of the same fiber in an oven at a temperature that is similar to the one used during the road construction for five hours. Color, volume and shape must be observed and recorded.

Table 2 Physical properties of fibers that are commonly used as reinforcements in HMA. Adapted from [28]

\begin{tabular}{lllll} 
Fiber & $\begin{array}{l}\text { Tensile Strength } \\
(\mathrm{Gpa})\end{array}$ & $\begin{array}{l}\text { Modulus of } \\
\text { Elasticity (Gpa) }\end{array}$ & Mohs Hardness & $\begin{array}{l}\text { Specific Gravity } \\
\left(\mathrm{g} / \mathrm{cm}^{3}\right)\end{array}$ \\
\hline Asbestos & 2.1 & 11.70 & $2.50-4.00$ & $2.4-2.6$ \\
Aramid & 2.75 & 62.00 & $\mathrm{~N} / \mathrm{A}^{\mathrm{a}}$ & 1.44 \\
Acrylic & 0.88 & 17.70 & $\mathrm{~N} / \mathrm{A}^{\mathrm{a}}$ & 1.18 \\
Carbon & 1.33 & 30.00 & 6.00 & 2.60 \\
Glass & 3.40 & 72.00 & 6.50 & 2.50 \\
Steel & 0.95 & 11.00 & 5.00 & 7.50 \\
Mineral & 1.50 & 70.00 & 6.00 & 2.70 \\
Ceramic & 1.10 & 152.00 & 6.00 & 1.70 \\
\hline
\end{tabular}

a. Not Available

With respect to their mechanical properties, aramid, carbon, asbestos and glass fibers report higher tensile strength than acrylic, mineral and ceramic fibers. It is important to point out that high values of tensile strength suggest high values of modulus of elasticity; therefore, those fibers seem to provide the mixture with elastic performance.

According to Chen and Xu [2], lignin and asbestos fibers have a water absorption of $28.14 \%$ and $23.12 \%$, respectively, which are higher values than those of polyacrylonitrile and polyester fibers: $10.97 \%$ and $9.94 \%$, respectively. Lignin fibers changed their color from light gray to dark green while asbestos fibers changed from gray to light yellow. Polyester and polyacrylonitrile do not change their color or volume, which suggests that they have a low susceptibility to water. Finally, Xiong et al. [4] reported that lignin and polyester fibers are more sensitive to humid environments than mineral fibers (basalt and brucite).

Regarding their thermostability, polyester fibers do not present changes in volume and shape. On the other hand, lignin fibers, made from wood and plants, have low thermostability as their volume decreases with heat. Mineral fibers like basalt and brucite present better thermostability than polyester [4], as shown in Table 3 . Furthermore, other tests like differential scanning 
Author's post-print: Carlos Slebi-Acevedo, Pablo Lastra-González, Pablo Pascual-Muñoz, Daniel Castro-Fresno. “Mechanical performance of fibers in hot mix asphalt: a review". Construction and Building Materials 200 (2019), 756-769. ISSN 09500618. DOI: 10.1016/j.conbuildmat.2018.12.171

calorimetry (DSC) can be carried out to study the effect of heat. Park et al. [53] suggest that the fiber drying process leads to changes in the pore size distribution, thus restricting the swelling of the fibers.

Table 3. Water absorption and thermostability of fibers. Adapted from $[4,54]$

\begin{tabular}{lll} 
Fiber type & $\begin{array}{l}\text { Average } \\
\text { water } \\
\text { absorption } \\
(\%)\end{array}$ & $\begin{array}{l}\text { Mass loss } \\
(\%)\end{array}$ \\
\hline Brucite & $1.07 \%$ & $0.72 \%$ \\
Lignin & $15.49 \%$ & $1.84 \%$ \\
Basalt & $1.17 \%$ & $0.56 \%$ \\
Polyester & $2.43 \%$ & $0.95 \%$ \\
Polyacrylonitrile & $10.97 \%$ & $\mathrm{~N}^{\mathrm{a}} \mathrm{A}^{\mathrm{a}}$ \\
Asbestos & $23.12 \%$ & $\mathrm{~N} / \mathrm{A}^{\mathrm{a}}$ \\
\hline
\end{tabular}

a. Not Available

\subsubsection{Microstructure test}

The microstructure of the fibers has been deeply evaluated as it helps to establish their structure, pore content, weaved branches and estimate the specific surface area [55]. The microstructure can be studied through a scanning electron microscope (SEM), which produces images of a sample by scanning its surface with a focused beam of electrons [56]. SEM analysis is a good procedure to measure the specific surface area, which is a property that enables the relation of the absorption and adhesion of the fibers to the asphalt [57]. Asbestos fibers present little branches, meaning lower specific area compared to lignin fibers, which have rough surface texture and a greater specific surface area. This implies that these fibers absorb more binder and therefore, prevent drain down. Polyester fibers have antenna characteristics at their ends, which provides the bitumen greater stiffness. Pores on the cellulose fibers have a relatively flat cross section in their filaments, thus resulting in an increase of the fiber surface area. Mineral fibers present a more rigid structure as compared to the more flexible carbon fibers [57]. In general, ceramic fibers present a smooth surface, so not requiring additional asphalt binder when they are added to the asphalt mixture [58]. Because of the shape, several fibers can interlock together and form a network with the asphalt, which results in stronger connections and lower risk of crack propagation. The fact that the images do not have coalescence should be taken into account as it means that the fibers can be distributed in asphalt binder homogenously [58]. Finally, Gao and Wu [59] stated that the lipophilicity of basalt fibers as well as their coating ability (by bitumen) are very strong. In fact, the propagation of microcracks in asphalt can be delayed due to basalt fibers crossing through the micropores, thus fixing the internal defects of the material.

\section{Characterization of fibers in bitumen}

Several investigations have proved that fibers can be used to prevent asphalt binder drain down during mixing, transportation and compaction processes of asphalt mixes, particularly in asphalt 
Author's post-print: Carlos Slebi-Acevedo, Pablo Lastra-González, Pablo Pascual-Muñoz, Daniel Castro-Fresno. “Mechanical performance of fibers in hot mix asphalt: a review". Construction and Building Materials 200 (2019), 756-769. ISSN 09500618. DOI: 10.1016/j.conbuildmat.2018.12.171

concretes (AC), stone matrix asphalts (SMA), and porous asphalts (PA) [11,57]. It has been shown that fibers can reinforce the asphalt mastic through the generation of a three-dimensional network, thus improving the mix adhesion $[60,61]$. Fibers provide the bitumen with viscoelastic behavior, which results in good performance of the pavement structure. Viscous components prevent cracking at low temperatures while elasticity prevents rutting at high temperatures [62].

\subsection{General characterization tests}

To assess the bitumen properties, the most common tests are penetration, softening point and viscosity tests. Alrajhi [62] manufactured asphalt mixes with different dosages of polypropylene and aramid fibers. Binder test results indicated that the highest viscosity with the least temperature susceptibility to both permanent deformation and thermal cracking was provided by the blend with three parts polypropylene and one of aramid. Aramid increased the viscosity of the bitumen to a certain point, but beyond that point, it began to decrease, as the fiber did not melt in the binder and started to accumulate. Mohammed et al. [5] studied the effect of glass and cellulose fibers in the bitumen for concentrations by volume of $0.5 \% ; 1.0 \%$ and $2.0 \%$. It was found that the penetration value decreases with the addition of glass and cellulose fibers. Moreover, the use of these fibers was reported to increase the softening point and the viscosity of bitumen. Glass fibers form a continuous network in the bitumen and reinforce it, while bitumen with cellulose fibers exhibits a more limited increase in viscosity, which could be due to the greater dispersion of those fibers.

It is important to take into account that an excess of fibers can cause the mastic to become fragile. The workability of the bitumen should also be considered. Thus, using a bitumen with a high content of fibers can lead to difficulties in the blending process of the asphalt mixture. Wu et al. [61] incorporated three different types of fibers into bitumen in order to measure its viscosity. They found that concentrations of $0.3 \%$ lignin fibers and $4 \%$ carbon fibers by weight of bitumen provides the binder with the optimum reinforcement, whereas mixing more fibers could be uneconomic or make the bitumen more brittle, which ultimately would result in pavement deterioration. The length of the fibers also affects the viscosity of the binder. Fu et al. [63] determined that short fibers increased the viscosity to a lesser extent than long fibers. On the other hand, even though the expected viscosity is easier to achieve with long fibers, they may cause blending problems. Finally, it should be mentioned that increasing the viscosity of the bitumen can improve its performance at high temperature, thus reducing the risk of rutting of the road pavement $[61,64]$.

\subsection{Characterization of fibers in bitumen at intermediate and high temperature}

The foremost tests to characterize shear resistance and viscoelastic behavior of bituminous materials modified with fibers are the cone penetration test and the dynamic shear rheometer (DSR) test (ASTM D7175-15) [65]. The sink cone penetration test developed by Xu et al. [54] and applied to other projects $[18,66]$ consists of pushing a cone into the fiber-reinforced asphalt mix until a stable situation is reached. Then, the sink depth is measured and recorded. Based on the strength of the balance theory [2], the shear stress of the bitumen can be determined. Mineral fibers are reported to have a great effect in increasing the shear stress as compared to lignin fibers [61]. The reason for this may be that long mineral fibers increase the viscosity of asphalt more significantly than the short lignin fibers [63]. Fibers can absorb the light components of bitumen such as aromatics and resins, which actually increases the viscosity and reduces the 
Author's post-print: Carlos Slebi-Acevedo, Pablo Lastra-González, Pablo Pascual-Muñoz, Daniel Castro-Fresno. “Mechanical performance of fibers in hot mix asphalt: a review". Construction and Building Materials 200 (2019), 756-769. ISSN 09500618. DOI: 10.1016/j.conbuildmat.2018.12.171

219

cone sink depth. Similarly, it can be said that fibers with higher tensile strength, such as polyester and polyacrylonitrile fibers, can lead to higher viscosities and shear resistances with respect to binders with lignin and asbestos fibers [2]. The microstructure of the fibers also affects their viscosity and resistance parameters. Several types of fibers such as glass, polyester and polyacrylonitrile have a rather rigid antenna tip, which enables the generation of a bond between the asphalt and the fiber and prevents the propagation of cracks [5]. Other authors [61] have applied this test in asphalt mortars with fibers; Table 4 shows the results of cone sink depth and shear stress for different types of fibers.

Table 4. Results of shear stress from the sink cone test for different types of fibers.

\begin{tabular}{|c|c|c|c|c|}
\hline Citation & Fiber type & $\begin{array}{l}\text { Fiber fraction } \\
(\%)\end{array}$ & $\begin{array}{l}\text { Cone } \\
\text { Sink } \\
\text { Depth } \\
(\mathrm{mm})\end{array}$ & Shear stress (Mpa) \\
\hline \multirow[t]{3}{*}{ [61] } & Carbon & $4.00 \%$ & 29.00 & $50.00^{b}$ \\
\hline & Mineral & $0.30 \%$ & 24.00 & $73.00^{b}$ \\
\hline & Lignin & $0.40 \%$ & 28.00 & $54.00^{b}$ \\
\hline \multirow[t]{5}{*}{ [4] } & Non-fiber & - & 16.00 & 8.23 \\
\hline & Brucite & $0.45 \%^{a}$ & 9.62 & 22.93 \\
\hline & Lignin & $0.30 \%^{\mathrm{a}}$ & 11.80 & 15.20 \\
\hline & Basalt & $0.30 \%^{\mathrm{a}}$ & 9.24 & 24.85 \\
\hline & Polyester & $0.30 \%^{\mathrm{a}}$ & 7.30 & 39.88 \\
\hline \multirow[t]{4}{*}[57]{} & Non-fiber & $0 \%$ & 2.83 & $141.00^{b}$ \\
\hline & Carbon & $1.00 \%$ & 2.61 & $166.00^{b}$ \\
\hline & mineral & $1.00 \%$ & 1.70 & $393.00^{b}$ \\
\hline & cellulose & $1.00 \%$ & 2.67 & $159.00^{\mathrm{b}}$ \\
\hline \multirow[t]{6}{*}{ [2] } & Non-fiber & $0.00 \%$ & 27.60 & 7.28 \\
\hline & Polyester I & $0.30 \%^{\mathrm{a}}$ & 6.25 & 141.87 \\
\hline & Polyester II & $0.30 \%^{\mathrm{a}}$ & 5.10 & 213.07 \\
\hline & Polyacrylonitrile & $0.30 \%^{\mathrm{a}}$ & 5.12 & 211.41 \\
\hline & Lignin & $0.30 \%^{\mathrm{a}}$ & 9.44 & 62.19 \\
\hline & Asbestos & $0.30 \%^{\mathrm{a}}$ & 16.06 & 21.49 \\
\hline
\end{tabular}

a. by weight of mixture

b. shear stress determined in fiber modified asphalt mortar.

229 Rheological properties can be improved with the addition of fibers either in the mastic or in the binder [67]. Mohammed et al. [5] found a marked influence of fibers on the complex modulus $\left(\mathrm{G}^{*}\right)$ of binders with $1 \%$ and $2 \%$ fibers at low frequencies and high temperatures $\left(50^{\circ} \mathrm{C}-70^{\circ} \mathrm{C}\right)$. Thus, adding $1 \%$ cellulose and glass fiber resulted in a complex modulus seven and four times higher than for a bitumen alone. This increase might be caused by the three-dimensional small fiber network generated in the bitumen. Although fiberglass has a higher modulus of elasticity and higher tensile strength, better results of complex modulus were obtained with the cellulose 
Author's post-print: Carlos Slebi-Acevedo, Pablo Lastra-González, Pablo Pascual-Muñoz, Daniel Castro-Fresno. “Mechanical performance of fibers in hot mix asphalt: a review". Construction and Building Materials 200 (2019), 756-769. ISSN 09500618. DOI: 10.1016/j.conbuildmat.2018.12.171

fibers. This is because the glass fibers are oriented in only one direction whereas the cellulose fibers, according to their microstructure, present random directions, which can make the bond between the binder and the fibers stronger. Xiong et al. [4] pointed out that the addition of fibers in the asphalt mastic increased the complex modulus, especially at high temperatures. Therefore, better rutting resistance would be obtained by using brucite fibers, as these can prevent the high temperature creep of pavements under traffic loads. Khattak et al. [20] studied the effect of carbon nano fibers in asphalt binder and concluded that the mixing process had an impact on the viscoelastic properties of the asphalt binder. Likewise, the addition of fibers has been shown to decrease the value of the phase angle in such a way that the behavior of the asphalt becomes more elastic. This is particularly good at high temperatures and low frequencies because it improves the resistance to permanent deformation in the bitumen $[27,68]$. The rutting parameter $G^{*} / \sin (\delta)$ is an indicator of the resistance to permanent deformation of the binder in the mixture. Table $\mathbf{5}$ shows the effect of two types of glass fibers and one cellulose fiber added to the binder [5]. It should be noted that the addition of fibers increases the rutting at intermediate temperatures, which indicates that a proper dispersion of fibers in the bitumen reduces the plastic deformation.

Table 5. Rutting parameter $G * / \sin (\delta)$ at different temperatures. Adapted from [5]

\begin{tabular}{llllll} 
Fiber type & \multicolumn{5}{l}{ Temperature $\left({ }^{\circ} \mathrm{C}\right)$} \\
\hline & 50 & 55 & 60 & 65 & 70 \\
\hline Base binder & 8.80 & 4.10 & 2.20 & 1.60 & 0.90 \\
$0.5 \%$ vol Glass I & 10.50 & 5.00 & 2.50 & 1.70 & 0.90 \\
$0.5 \%$ vol Glass s & 11.90 & 5.80 & 2.70 & 1.80 & 1.00 \\
$0.5 \%$ vol cellulose & 11.90 & 6.10 & 3.00 & 1.90 & 1.00 \\
\hline
\end{tabular}

\subsection{Characterization of fibers in bitumen at low temperature.}

As is very well known, bitumen becomes more brittle at low temperatures. The use of fibers has proven to be an option to provide the asphalt binder with greater ductility and guarantee more viscoelastic behavior, thus improving toughness, fracture and post cracking energy $[19,69,70]$. The Bending Beam Rheometer (BBR) test is commonly used to evaluate bitumen performance at low temperatures. However, to assess the fiber-binder interaction pull-out and direct tensile tests are used. It is also known that the role played by fibers in composites and fragile materials is to provide them with ductility; where cracks occur, fibers serve as a bridge to delay the crack growth. Qian et al. [19] performed pull-out tests on polyester and aramid fibers of the same length embedded in conventional and modified asphalt binders. The aramid fibers showed values of pull-out resistance of up to $3700 \mathrm{MPa}$, five times higher than those of polyester fibers (Table 6). Similarly, the tensile strength and modulus of elasticity of aramid fibers are five times greater than those of polyester fibers. Finally, it was reported that regardless of the type of bitumen used, whether it was modified or not, the pull-out resistance values were very similar for each type of fiber used.

Regarding direct tensile tests (DTT), polyester fibers were selected to be investigated since, according to the authors, this is a viable material for manufacturing processes [19]. The study concluded that failure is more ductile when fibers have been added. Although cracks can occur, fibers prevent their propagation. Regarding the optimal dosage, adding $4 \%$ polyester fibers to 
Author's post-print: Carlos Slebi-Acevedo, Pablo Lastra-González, Pablo Pascual-Muñoz, Daniel Castro-Fresno. “Mechanical performance of fibers in hot mix asphalt: a review". Construction and Building Materials 200 (2019), 756-769. ISSN 09500618. DOI: 10.1016/j.conbuildmat.2018.12.171

the bitumen resulted in maximum strength of $3 \mathrm{MPa}$ and failure tensile strain of $6 \%$. In both cases, results are higher than those obtained for a conventional binder: 2.3 MPa maximum strength and $0.2 \%$ failure tensile strain [19]. As for a tafpack super (TPS) modified asphalt, maximum strength and failure tensile strain of $4.35 \mathrm{MPa}$ and $3 \%$ were reached, respectively. The reason for these results is probably the fact that a TPS modified binder is more viscous [71], in spite of which, its failure strain increased. In terms of the fiber length, better results of the Multi-fiber pull-out test are obtained when long fibers $(15 \mathrm{~mm})$ are used, even though a good distribution within the binder is difficult to achieve. On the other hand, short fibers can be properly scattered but no reinforcement is achieved. An optimal length of $6 \mathrm{~mm}$ was found to guarantee the best performance in terms of strength and deformation [19].

Table 6. Pull-out test results for different fibers and types of binders and mortars. Adapted from [19]

Asphalt type Fiber type Embedment Fiber pulllength $(\mathrm{mm})$ out strength

(MPa)

\begin{tabular}{llll}
\hline Normal & Polyester & 4 & 334 \\
asphalt & & 6 & 579 \\
binder & & 12 & 703 \\
& & 19 & 764 \\
& & 24 & 602 \\
& Aramid & 6 & 2722 \\
& & 12 & 3124 \\
& & 19 & 3774 \\
TPS & & 26 & 2923 \\
modified & Polyester & 6 & 509 \\
asphalt & & 12 & 716 \\
& & 30 & 738 \\
Asphalt & Aramid & 12 & 3222 \\
mortar & Polyester & 12 & 519 \\
& Aramid & 12 & 3287 \\
& & 9 & 3527 \\
\hline
\end{tabular}

\subsection{Mesh basket drain down test}

The use of fibers in bitumen is an alternative to prevent binder drain down [72]. Depending on their microstructure, specific surface and texture [18,55], fibers are capable of fulfilling the role of absorbing the light components of the binder and building a bonding interface between fiber and binder. Although there already is a test that measures drain down characteristics in uncompacted hot mix asphalts (AASHTO T 305) [73], some authors have designed a new test to evaluate the absorption of bitumen in fibers and analyze their adhesion and stabilization $[4,74]$. Based on this test, Xiong et al. [4] stated that lignin fibers display the highest bitumen absorption rate, with only $3.04 \%$ binder mass loss. Mixes with brucite, basalt and polyester fibers showed $8.17 \%, 12.32 \%$ and $18.13 \%$ binder mass loss, respectively. These tests were carried out with $6 \%$ by weight of binder in the mixture, at a temperature of $160{ }^{\circ} \mathrm{C}$ for 30 minutes. Similarly, Chen et al. [74] showed that lignin fibers provided the lowest binder drop compared to asbestos, polyester and polyacrylonitrile fibers (Table 7). Oda et al. [72] reported the use of natural fibers 
Author's post-print: Carlos Slebi-Acevedo, Pablo Lastra-González, Pablo Pascual-Muñoz, Daniel Castro-Fresno. “Mechanical performance of fibers in hot mix asphalt: a review". Construction and Building Materials 200 (2019), 756-769. ISSN 09500618. DOI: 10.1016/j.conbuildmat.2018.12.171

298

299

300

301

302

303

304

305

306

307

308

like coconut fibers. Based on this study, binder absorption was improved to a higher extent than with polyester fibers. Regarding the other two parameters mentioned before, organic fibers (lignin, coconut, cellulose) and brucite fibers have larger specific surface areas and rough surfaces, unlike polymeric fibers (polyester, polyacrylonitrile), with smaller specific surface areas and smoother surface texture [75]. Rougher surface textures are linked to higher values of bonding strength with asphalt whereas binder absorption by fibers will lead to higher viscosities, stronger fiber-binder adhesion and thicker binder films. All the above will ultimately mean good properties of the asphalt mixture in terms of anti-cracking propagation, flexibility, fatigue and aging resistance $[74,76]$.

Table 7. Results of mesh basket drain down test at different temperatures. Adapted from [2]

\begin{tabular}{|c|c|c|c|c|c|}
\hline \multirow[t]{2}{*}{ Temperature } & \multirow{2}{*}{$\begin{array}{l}\text { Asphalt separation } \\
(\%)\end{array}$} & \multicolumn{4}{|c|}{ time (min) } \\
\hline & & 30 & 60 & 90 & 120 \\
\hline \multirow[t]{5}{*}{ 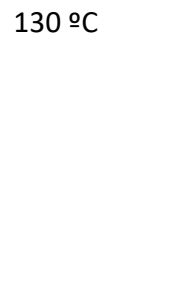 } & Polyester fiber I & 2.25 & 6.00 & 8.75 & 8.76 \\
\hline & Polyester fiber II & 2.35 & 6.17 & 9.03 & 9.04 \\
\hline & $\begin{array}{l}\text { Polyacrylonitrile } \\
\text { fiber }\end{array}$ & 22.95 & 25.20 & 26.32 & 26.33 \\
\hline & Asbestos fiber & 1.25 & 6.50 & 10.50 & 13.50 \\
\hline & Lignin fiber & 0.00 & 0.00 & 0.00 & 0.00 \\
\hline \multirow[t]{5}{*}{$140 \stackrel{\circ}{C}$} & Polyester fiber I & 8.25 & 12.25 & 14.50 & 18.50 \\
\hline & Polyester fiber II & 8.55 & 12.29 & 14.56 & 19.13 \\
\hline & $\begin{array}{l}\text { Polyacrylonitrile } \\
\text { fiber }\end{array}$ & 23.75 & 26.25 & 27.50 & 28.00 \\
\hline & Asbestos fiber & 4.75 & 9.75 & 14.25 & 18.25 \\
\hline & Lignin fiber & 0.00 & 0.04 & 0.08 & 0.11 \\
\hline $170 \stackrel{\circ}{C}$ & Lignin fiber & 2.00 & 3.50 & 3.60 & 4.00 \\
\hline
\end{tabular}

\section{Mechanical impact of fibers in asphalt mixtures}

According to the European Asphalt Pavement Association (EAPA), Europe and the United States produced 265.4 and 319 million tons of asphalt mixtures in 2014, respectively [77]. The above has aroused the interest in improving the performance of asphalt mixtures, in particular, their mechanical properties and functionality on the road. The addition of fibers has been considered for reinforcement of composite materials such as asphalt mixtures $[78,79]$.

Regarding blending procedures, there are pre-established procedures for the preparation of asphalt mixtures with conventional bitumen; however, there is a lack of protocols on how asphalt mixtures should be made when new materials such as fibers are incorporated [80]. Two methods are commonly known. The first method is called wet procedure. In this method, the fibers are previously mixed with the binder before aggregates and filler are incorporated. In this technique a good dispersion between fibers and bitumen should be achieved in order to avoid the formation of clusters; the combination of sonication and high shear mixing procedures helps to achieve a high degree of dispersion [20]. The second method is known as dry procedure and consists of mixing fibers and aggregates before bitumen is incorporated to the blend [24]. In 
Author's post-print: Carlos Slebi-Acevedo, Pablo Lastra-González, Pablo Pascual-Muñoz, Daniel Castro-Fresno. “Mechanical performance of fibers in hot mix asphalt: a review". Construction and Building Materials 200 (2019), 756-769. ISSN 09500618. DOI: 10.1016/j.conbuildmat.2018.12.171

general, the dry procedure is the most used as it enables a good dispersion of the fibers and reduces the variability in the experimental tests of the asphalt mixtures $[24,81,82]$. Asphalt plants usually have special mechanisms to add fibers and other additives into the asphalt mixtures during production. For example, some plants keep the fibers in dry conditions and increase the mixing time to avoid the formation of fiber bundles in the mixture. Furthermore, if asphalt plants do not follow these procedures, the incorporation of fibers can be done manually [83]. Other investigations suggest incorporating the fibers after the bitumen has been mixed with the aggregates and the filler [84].

Previous research indicates that the optimum use of the fibers in asphalt mixtures requires an additional binder content in order to properly coat the surface of the added fibers. In addition, because of their microstructure, specific surface area and texture, fibers can absorb the light components of the bitumen $[7,85]$. If the mixing and production guidance is not taken into account, a reduction in the mechanical resistance of the asphalt mixture can occur [74].

Asphalt concrete is traditionally the most commonly used type of mixture in the construction of roads, highways and airports [86]. For its use as road course, structural requirements have to be fulfilled. The mechanical behavior is linked to the bitumen used and depends strongly on temperature [87]. At high temperatures, bitumen becomes soft, which may lead to permanent deformation of the asphalt concrete [88]; at intermediate temperature, failures due to fatigue may occur because of traffic loads. Finally, at low temperature, thermal shrinkage cracking is prone to occur.

Regarding porous friction courses (PFC), fibers have contributed to diminish certain conditions. Thus, porous asphalt mixtures with polyethylene fibers have shown binder drain down reductions of up to $46 \%$ as compared to unmodified ones [89]. Tensile strength, permanent deformation and moisture susceptibility have also been improved. Similarly, Tanzadeh and Shahrezagamasaei [90] reported $80 \%$ reduction in asphalt binder drain down when adding $0.2 \%$ glass fiber and $0.3 \%$ polypropylene fibers to PFC asphalt mixtures.

Two aspects have to be considered in the design of asphalt mixtures. First of all, the mechanical resistance, where parameters like stiffness, breaking strength, fatigue, rutting or particles loss (in porous asphalt mixtures) have to be taken into account for the mixture design. The second aspect relates to the mixture performance, where pavement section, visibility and glare, noise, and environmental awareness are crucial elements [91]. In this section, the first aspect is covered by introducing the effect of the fibers in the reinforcement of asphalt concrete under different temperatures, as well as establishing the influence of fiber parameters such as type, length, diameter and content on the fiber-reinforced asphalt mixture (FRAM) performance.

\subsection{Improving the mechanical performance of mixes by using fibers}

This section presents the most promising fibers, i.e. those that have shown good mechanical properties in HMA over recent years. Table 8 shows the advantages and potential drawbacks that using fibers in different asphalt mixtures can cause. Table 9 quantitatively summarizes the results obtained from the literature regarding the maximum improvements achieved in the mechanical performance of asphalt mixtures when different types of fibers are incorporated into a conventional blend. 
Author's post-print: Carlos Slebi-Acevedo, Pablo Lastra-González, Pablo Pascual-Muñoz, Daniel Castro-Fresno. “Mechanical performance of fibers in hot mix asphalt: a review". Construction and Building Materials 200 (2019), 756-769. ISSN 09500618. DOI: 10.1016/j.conbuildmat.2018.12.171

\subsubsection{Mineral fibers}

Qin et al. [18] studied the effect of incorporating different proportions of basalt fibers in asphalt mastics, the fibers having different lengths. The most appropriate fiber content was found to be between $5 \%$ and $7 \%$. As for the length of the fibers, $6 \mathrm{~mm}$ provided best mix performance. An excess of fibers higher than $10 \%$ can cause a clustering effect, thus reducing the homogeneity of the asphalt mastic. With the incorporation of the fibers, the properties of the mastic that improved the most were binder adsorption, strength behavior and crack resistance. According to Zhang et al. [92], the addition of $0.1 \%$ and $0.2 \%$ basalt fibers resulted in deflection reductions of $13.4 \%$ and $34.6 \%$, respectively, at $3600 \mathrm{~s}$ and $-10^{\circ} \mathrm{C}$. The authors concluded that basalt fibers enhance the low-temperature performance of the asphalt mortar, acting as a matrix plus fiber composite. Xiong et al. [4] investigated the effect of brucite fibers and basalt fibers on asphalt concrete. Results indicated great high-temperature stability, low-temperature cracking resistance and moisture susceptibility. Magnesium hydroxide, which is one of the main components of brucite fibers, provides a good alkalinity condition if fibers are mixed with aggregates and filler with compatible polarity.

\subsubsection{Polyester fiber}

The use of polyester fibers in conjunction with lower contents of binder enables the increase of resistance to fatigue and plastic deformation, transferring the force from the mineral structure to the fiber-reinforced mastic [75]. Wu et al. [93] studied the mechanical properties of the polyester fiber asphalt concrete (PFAC) and found that the resistance to adhesion between fibers and asphalt cement is directly linked to the percentage of fibers and the bitumen content. After evaluating nine different mix designs using the Marshall method, the authors concluded that the optimum content of polyester fibers was $0.15 \%$ by weight of mixture.

Polyester fibers have already been successfully applied to road construction. Actually, 6.35-mm long fibers were used in a pavement in the city of Tacoma, which did not register degradation during 4 years of use [94]. Based on a field road application operated by the Pennsylvania Department of Transportation, Maurer and Malasheskie [95] reported that adding polyester fibers was effective at reducing reflective cracking. Chen et al. [74] recommend a polyester fiber content of $0.35 \%$ by weight of mixture for the AC16. Wu et al. [96] reported an increase in the number of cycles to fatigue failure of a fiber-modified asphalt mixture, with 1.9, 2.9 and 3.6 times more cycles at $0.5,0.4$ and 0.3 stress ratios (stress levels according to the splitting strength of the asphalt mixture), respectively, for an incorporation of $0.3 \%$ polyester fibers. Likewise, Freeman et al. [97] and Kim et al. [98] reported improvements of $15 \%$ and $5 \%$ in the indirect tensile strength, respectively, after adding $0.35 \%$ polyester fibers ( $6 \mathrm{~mm}$ long) by weight of $\checkmark$ asphalt mixture. According to Lauke et al. [63] fibers with relatively greater length/diameter ratio can interlock better to form a networking system.

\subsubsection{Polyacrylonitrile fibers}

Yao et al. [99] incorporated PAN fibers into asphalt concrete (4\% and $6 \%$ fibers by weight of binder) by the wet method. Regarding the results of the DSR test for the fiber-modified asphalt mortar, the authors reported an increase in the factor $\mathrm{G}^{*} / \sin \delta$ with the incorporation of fibers. Because of that, the stability of the binder at high temperatures increased and the permanent deformation decreased. When comparing with cellulose fibers, it can be noticed that after adding the same percentage of fibers (4\%), the viscosifying action of polyacrylonitrile fibers is 1.8 times greater than that of cellulose fibers. Besides, rutting resistance of dense asphalt 
Author's post-print: Carlos Slebi-Acevedo, Pablo Lastra-González, Pablo Pascual-Muñoz, Daniel Castro-Fresno. “Mechanical performance of fibers in hot mix asphalt: a review". Construction and Building Materials 200 (2019), 756-769. ISSN 09500618. DOI: 10.1016/j.conbuildmat.2018.12.171

409

410

411

412

413

414

415

416

417

418

419

420

421

422

423

424

425

426

427

428

429

430

431

432

433

434

435

436

437

438

439

440

441

442

443

444

445

446

447

448

449

450

451

452

mixtures with PAN fibers is about 2.2 times higher than with cellulose fibers for the same fiber content. However, the optimal asphalt content of PAN-reinforced mixtures is actually higher [99] as polyacrylonitrile fibers have a higher absorption rate. These types of fibers also have a positive impact on the moisture susceptibility of the asphalt mixtures, as observed by Chen et al. [74] and Yao et al. [99]. Finally, polyacrylonitrile has shown great affinity to bitumen, which has aided in the synthesis of new materials such as carbon nanotubes, which have already been implemented in asphalt binders and mixtures $[41,46,100]$.

\subsubsection{Carbon fibers}

It is common to find that these fibers are added either by the wet or dry method; in the case of the wet process carbon nanofibers (CNFs) are usually added to modify the asphalt binder, while using the dry method is more related to the incorporation of micro and macro carbon fibers into the mix [51]. Khattak et al. [20] pointed out that a homogeneous dispersion of CNFs improves the viscoelastic and fatigue properties of the CNF-modified asphalt binder. These authors also noticed an increase in the complex modulus $\mathrm{G}^{*}$, which may be due to the crack-bridging mechanism by CNF. Jahromi [101] dosed several contents of CNFs by weight of asphalt mixture and obtained the optimum asphalt content for each one. In this case, the wet procedure was used.

According to Jahromi [101], a fiber content greater than $0.3 \%$ by weight of mixture increases the stability, reduces the flow number and increases the void content; likewise, nanofibers absorb part of the binder, thus leading to an increase in the content of voids in the mixture [101]. Furthermore, the addition of $0.4 \%$ nanofiber by weight of mixture results in higher resistance to permanent deformation, resilient modulus, and fatigue life. Moreover, moisture susceptibility can be improved by adding $1 \%$ microfibers by weight of bitumen, which also minimizes the deterioration caused by non-chloride de-icers [102]. 12-mm long carbon fibers were also investigated by Kim et al. [103], who incorporated them into the asphalt concrete by using the dry method. The authors reported that adding $1 \%$ fibers increases the flexural strength and the toughness value of the asphalt concrete by $12.1 \%$ and $65.5 \%$, respectively, when compared to a mixture without fibers. Other properties such as Tensile Strength Ratio (TSR), Marshall Stability and Indirect Tensile Strength (ITS) were not improved at all. In the same study, a SEM analysis allowed the authors to detect clumping of carbon fibers. Because of this, an uncorrect dispersion of the fibers is expected and hence, a negative impact on the mechanical properties of the asphalt material (as stated above).

The use of Polyacrylonitrile Carbon Fibers (PANCFs) for bitumen modification has become a new alternative to the use of ordinary polymer modifiers. Zhang et al. [104] added $5 \mathrm{~mm}$-long PANCFs to a conventional bitumen in a range of 0 to $0.12 \%$ by weight of binder. Results suggest not exceeding $0.1 \%$ fiber content in order to avoid aggregation and, therefore a negative effect on the mechanical performance of modified asphalts. Another study suggests that carbon fibers can stiffen the asphalt concrete and make it more resistant to rutting at high temperatures, increasing the tensile strength as well; nevertheless, improvements may not be noticed at lower temperatures [105]. Carbon fibers have been shown to perform well in asphalt mixtures, probably because the bitumen is a precursor of the carbon fibers [106]. In addition to providing the mixture with improved mechanical properties, the use of these fibers also enablesan increase in thermal conductivity and a decrease in the electrical resistance of the asphalt mixtures $[107,108]$. 
Author's post-print: Carlos Slebi-Acevedo, Pablo Lastra-González, Pablo Pascual-Muñoz, Daniel Castro-Fresno. “Mechanical performance of fibers in hot mix asphalt: a review". Construction and Building Materials 200 (2019), 756-769. ISSN 09500618. DOI: 10.1016/j.conbuildmat.2018.12.171

\subsubsection{Glass fibers}

Mahrez [109] studied the use of glass fibers in SMA mixtures. For this, $0.05 \%, 0.1 \%, 0.15 \%$, $0.20 \%, 0.25 \%, 0.3 \%, 0.4 \%$ and $0.5 \%$ fibers ( $10 \mathrm{~mm}$ long) by weight of mixture were incorporated by the dry method. It is important to bear in mind that a small variation of the fiber content in the mixture represents a large proportion of fiber content in bitumen. Thus, $0.2 \%$ fibers in a mixture equates to $4 \%$ fibers by weight of binder, which implies high viscosity and low workability in the blending procedure. The addition of fibers led to a decrease in the ductility of the binder and affected the rigidity and resilient modulus of the mixture. The best stability and flow values were found for a proportion of $0.2 \%$ by weight of mixture; however, this did not imply an improvement with respect to the sample without fibers. Moreover, adding glass fibers led to an increase in the mixture void content. This is because the contact between the aggregates decreases and fibers absorb the binder that coats the aggregates and fills the remaining gaps. In other research, Mahrez et al. [110] added 20-mm-long fiberglass to the SMA. The author reported an improvement in permanent strain and resilient modulus when adding less than $0.3 \%$ fibers. Moreover, fatigue life increased by $28.2 \%, 37.2 \%$ and $44.4 \%$ with the addition of $0.1 \%, 0.2 \%$ and $0.3 \%$ glass fiber, respectively.

Morea and Zerbino [111] also studied the effect of glass macro fibers in SMA. In this case, the authors incorporated fibers with lengths greater than $35 \mathrm{~mm}$. According to the results obtained, $0.4 \%$ glass fiber by weight of mixture is the optimum dosage to improve the rutting behavior and the maximum stress as determined in bending test. Guo et al. [112] reported good results regarding rutting resistance and fatigue properties in fiberglass-modified asphalt mixtures. Mohammed et al. [5] evaluated the influence of glass fibers on the rheological properties and toughness of bituminous binders. In this case, glass fibers provided the binder with improved toughness, which is linked to good fatigue behavior of the material. In fact, the addition of fibers significantly decreased the phase angle in the DSR test, giving the mastic a more elastic and less viscous performance. Thus, a $2 \%$ fiber increase (by volume) results in decreasing penetration, increasing softening point and viscosity and improved rutting resistance. In porous asphalt mixtures, adding $0.1 \%$ glass fibers and $0.3 \%$ polypropylene fibers led to a $65 \%$ increase in the tensile strength [90].

\subsubsection{Steel fibers}

Steel fibers are thought to offer more benefits than other types of fibers for the modification of asphalt mixtures. These fibers contribute to improving the electrical conductivity of the mixtures, which can be useful for the application of thermo- electrical techniques approaching the issue of freeze-thaw cycles on roads [113]; and especially for the self-healing and selfmonitoring of pavement structures [114]. Park et al. [115] studied the cracking resistance of a steel-fiber-reinforced asphalt concrete at low temperature. A large number of steel fiber variables were considered in terms of aspect ratio (length/diameter), section type and texture. The resulting asphalt mixtures were subjected to ITS at $-20{ }^{\circ} \mathrm{C}$ and results showed that the addition of fibers increased the ITS and toughness of the asphalt concrete. The length of the fibers had a positive impact on the properties evaluated. Reinforcing effects were not observed at all when the fiber length was under $6 \mathrm{~mm}$ or the fiber diameter was under $0.01 \mathrm{~mm}$. Hooked end or twisting fibers did not have a significant effect on improving the toughness of the mixture. On the other hand, twisted steel fibers of $30 \mathrm{~mm}$ long and $0.3 \mathrm{~mm}$ diameter exhibited the best results with a toughness improvement of $895 \%$. Steel fibers are dependent on temperature; therefore, their behavior in asphalt mixtures must be evaluated at high temperatures. Liu et al. 
Author's post-print: Carlos Slebi-Acevedo, Pablo Lastra-González, Pablo Pascual-Muñoz, Daniel Castro-Fresno. “Mechanical performance of fibers in hot mix asphalt: a review". Construction and Building Materials 200 (2019), 756-769. ISSN 09500618. DOI: 10.1016/j.conbuildmat.2018.12.171

498

499

500

501

502

503

504

505

506

507

508

509

510

511

512

513

514

515

516

517

518

519

520

521

522

523

524

525

526

527

528

529

530

531

532

533

534

535

536

537

538

539

540

541

542

543

[114] compared the fatigue resistance results of a steel-wool-reinforced porous asphalt beam with those of a non-fiber dense graded asphalt mixture at $20^{\circ} \mathrm{C} / 10 \mathrm{~Hz}$. Results were very similar, the characteristic strain being of 167 microstrains at one million cycles $\left(\varepsilon_{6}\right)$. The authors also studied the variation of the stiffness recovery of steel-wool-reinforced porous asphalt beams caused by induction heating. The authors concluded that induction heating helps to restore the stiffness of the steel-wool-reinforced porous asphalt when reaching an optimal temperature of $85^{\circ} \mathrm{C}$. García et al. [116] studied the effect of the diameter and length of steel wool fibers on dense asphalt concrete; the authors reported a reduction in the fiber length after the mixing and compaction processes. According to the authors, the reason is that fibers are subjected to shear, tensile stress and impacts during the mixing process [117]. Fibers with large diameter presented a smaller shortening in their length.

Clustering is more likely to happen when using long fibers $(\geq 7 \mathrm{~mm})$ rather than short ones $(\approx$ $2.5 \mathrm{~mm}$ ). The average percentage of clusters exhibited in mixtures with long fibers was $0.41 \%$, while it was of $0.35 \%$ with short fibers. In this sense, the authors reported that the percentage of clusters actually affects the voids in the mixture. More specifically, a higher percentage of clusters implies a greater number of voids. Accordingly, asphalt mixes with long fibers presented higher porosity, thus affecting the particle loss resistance. In general, the fact that fibers are not uniformly dispersed can have an effect in terms of particle loss [117]. Finally, according to Liu et al. [118], steel fibers with short length and big diameter have better strength reinforcement capability than fibers with long length and small diameter.

\subsubsection{Aramid fibers}

Aramid fibers have also been used for the modification of asphalt mixes. An addition of $0.045 \%$ aramid fibers by weight of asphalt mixture was employed in a road section in Tempe, Arizona [35]. The laboratory tests performed were: dynamic modulus, permanent deformation, fatigue resistance, crack propagation and Indirect Tension Test (ITT). Results showed that aramid fibers improve the performance of mixtures subjected to major pavement distresses such as rutting, fatigue cracking and thermal cracking [119,120]. Alrhaji [62] studied the effect of aramid and polypropylene fibers on asphalt mixtures and evaluated the results of dynamic modulus and ITS. Regarding the dynamic modulus, results of the fiber-modified mixtures increased with an increase in the amount of fiber. As for the ITT, the mixes with aramid fibers exhibited better results than those with polypropylene fibers; the best results in the dynamic test were obtained for mixes with polypropylene, though.

Based on the research done by Klinsky et al. [83] on the effect of polypropylene fibers and aramid fibers on HMA, it can be concluded that two different types of fibers can contribute in different ways to the performance of the asphalt mixture. On the one hand, polypropylene fibers provide adhesion and act as a dispersing agent. On the other hand, the aramid fibers provide a three-dimensional reinforcement network to the mixture. In this research, $0.05 \%$ fibers per ton of mixture were incorporated to the blend. Results showed lower permanent strain accumulation in the fiber-reinforced mixture than in the reference mixture. Moreover, the fibermodified mixture presented increases of $15 \%$ and $30 \%$ in the resilient modulus at $25^{\circ} \mathrm{C}$ and the dynamic modulus at elevated temperature, respectively, when compared to the reference mix. These results are certainly linked to an improved rutting resistance. Fracture resistance at intermediate temperature was also tested through the semicircular bending test. The area under the stress-strain curve was found to be $30 \%$ greater for the fiber-reinforced mixture than for the reference mixture, thus meaning an increase in the resistance to crack propagation and energy absorption due to fracture. Finally, it should be pointed out that the high degree of 
Author's post-print: Carlos Slebi-Acevedo, Pablo Lastra-González, Pablo Pascual-Muñoz, Daniel Castro-Fresno. “Mechanical performance of fibers in hot mix asphalt: a review". Construction and Building Materials 200 (2019), 756-769. ISSN 09500618. DOI: 10.1016/j.conbuildmat.2018.12.171

544 orientation of the aramid fibers, which is due to the relatively rigid polymer chains that are linked 545 by strong hydrogen bonds, enables a better transfer of the mechanical loads [48].

\subsubsection{Coconut fibers}

547 Coconut fibers, also known as coir, have become an alternative option for the replacement of 548 synthetic or non-renewable materials. The reason is the lower cost (and density) of these types 549 of natural fibers in comparison with synthetic fibers, which is due to their greater availability. 550 They are considered an environmentally friendly renewable resource on account of being a non551 polluting reused waste $[121,122]$. This type of fiber, when matured, accumulates a great amount 552 of lignite, which makes it stronger and less flexible. These fibers are also relatively impermeable, 553 making them less susceptible to damage by salt water [52]. Researches have reported that the most common use of these fibers has been in SMA mixtures, where fibers are required to hold the binder in the mixture and avoid drainage. In this research, $0.3 \%$ coconut fibers by weight of asphalt mixture was added to the blend that increased the stability and unit weight value of the mixture and decreased the flow number and air voids [123]. Likewise, ITSR, fatigue life and resilient modulus of SMA mixes increased independently of the binder used. Oda et al. [72] also reported high tensile strength and resilient modulus when using coconut fibers. Thulasirajan and Narasimha [124] indicated that $0.52 \%$ of $15-\mathrm{mm}$-long coconut fibers with $5.72 \%$ binder content provided the bituminous concrete with good stability and volumetric properties. Coconut fiberreinforced mixtures exhibited better results in the drain down test in comparison with mixtures having polyester or cellulose fibers. Overall, coconut fibers have proven to be a natural resource and a waste material suitable for the construction of flexible pavements. In porous asphalt mixtures more research is necessary as a higher content of fibers can increase the amount of air voids.

Table 8. Advantages and potential drawbacks of fibers in asphalt mixtures.

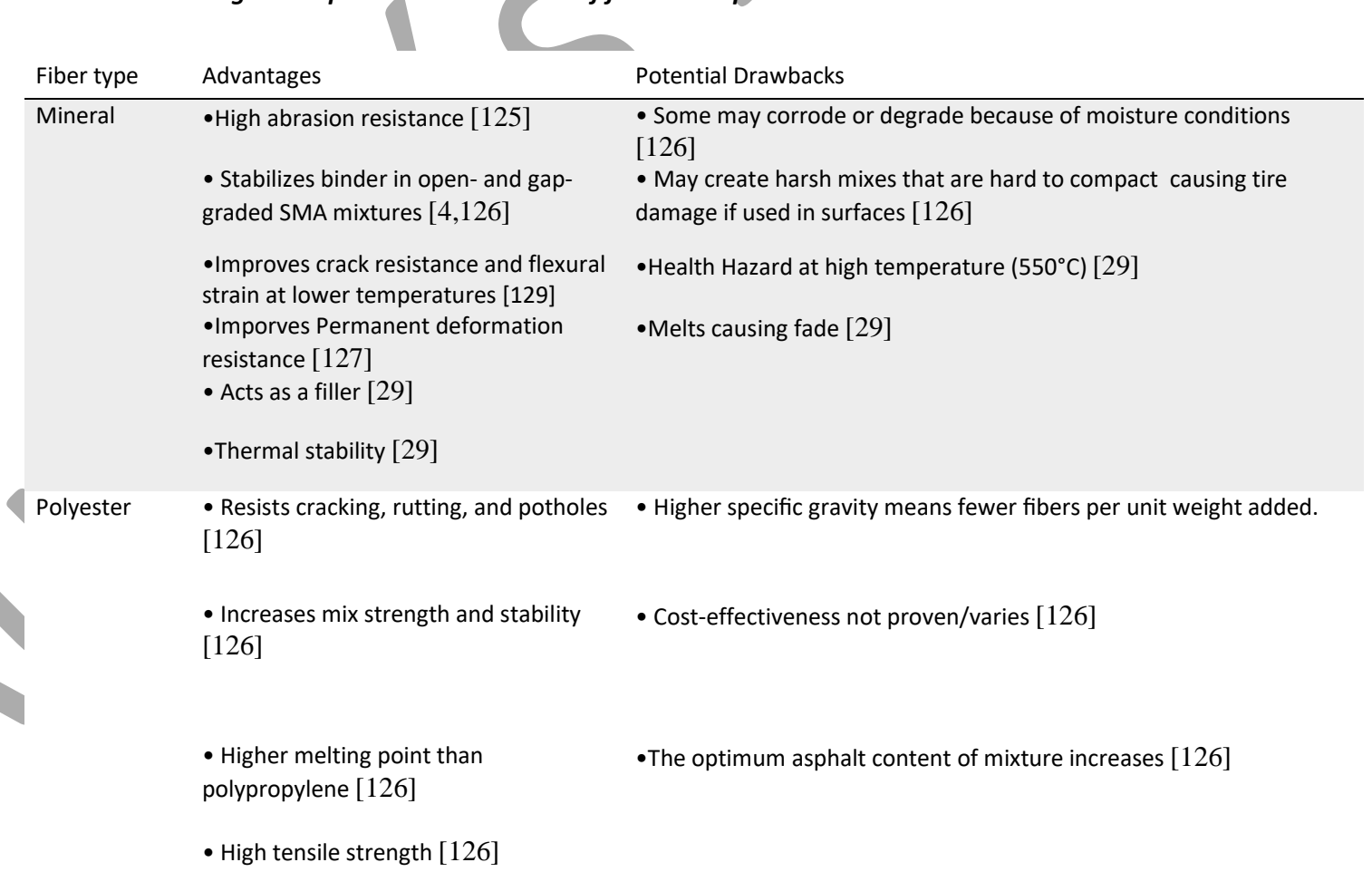


Author's post-print: Carlos Slebi-Acevedo, Pablo Lastra-González, Pablo Pascual-Muñoz, Daniel Castro-Fresno. “Mechanical performance of fibers in hot mix asphalt: a review". Construction and Building Materials 200 (2019), 756-769. ISSN 09500618. DOI: 10.1016/j.conbuildmat.2018.12.171

-Increases the fracture energy and

toughness [128]

-Improves high temperature stability,

increases the flexural strain at low

temperatures [129]

-Improves crack propagation resistance

[129,130]

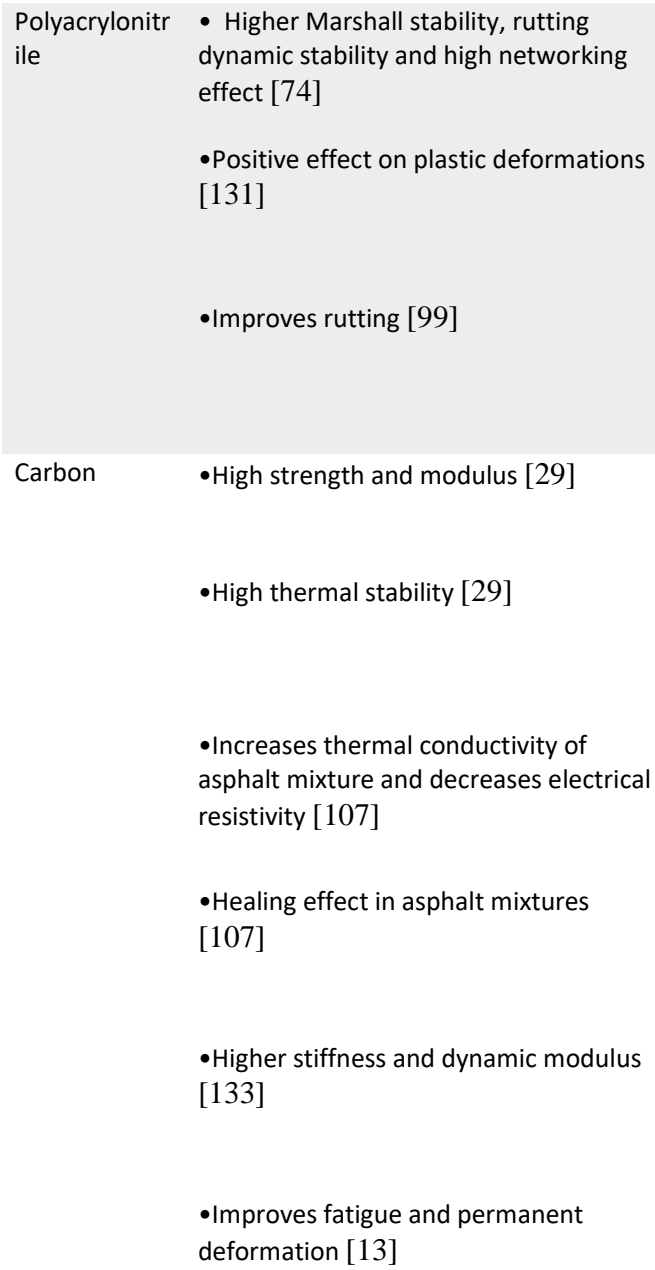

- Increases thermal conductivity of asphalt mixture and decreases electrical resistivity [107]

- Healing effect in asphalt mixtures [107]

-Higher stiffness and dynamic modulus [133]

- Improves fatigue and permanent deformation [13] 
Author's post-print: Carlos Slebi-Acevedo, Pablo Lastra-González, Pablo Pascual-Muñoz, Daniel Castro-Fresno. “Mechanical performance of fibers in hot mix asphalt: a review". Construction and Building Materials 200 (2019), 756-769. ISSN 09500618. DOI: 10.1016/j.conbuildmat.2018.12.171

- Higher residual stress capacity

$[90,111]$

•Increases rutting behavior [112]

-Increases tensile failure strain [134]

Steel

-Increases Marshall stability, rutting

-Poor distribution in mixture [117]

resistance, indirect tensile strength, and

low-temperature cracking resistance

[108]

-Self-healing properties $[135,136]$

-Does not have a relative influence on the particle loss resistance

[117]

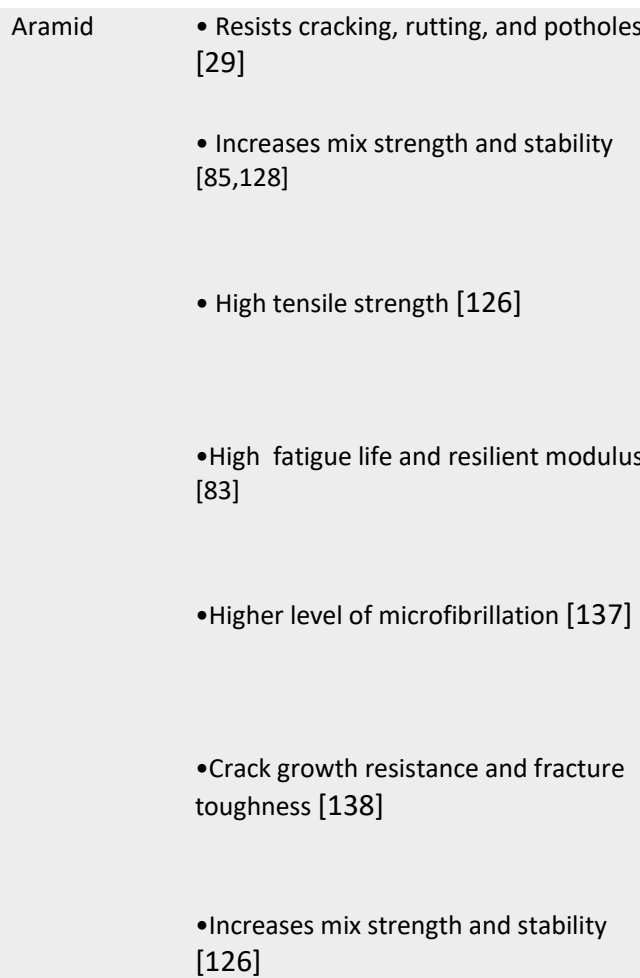

- Increases mix strength and stability $[85,128]$

- High tensile strength [126]

- High fatigue life and resilient modulus

[83]

-Higher level of microfibrillation [137]

- Crack growth resistance and fracture

toughness [138]

-Increases mix strength and stability

[126]

- Extra care to avoid non uniform fiber [29]

-Generally needs other ingredients in formulation [29]

Coconut $\quad$ Prevents drain-down during (Coir) production [52]

-Excess of fibers could reduce the contact between the aggregate

[139]

$\bullet 100 \%$ natural and ecological recycling

[140]

$\begin{array}{ll}\text { Cellulose } & \text { Stabilizes binder in open- and gap- } \\ & \text { graded stone matrix asphalt (SMA) } \\ & \text { mixtures }[10,126]\end{array}$

- Low strength and modulus $[29,126]$

mixtures $[10,126]$ 
Author's post-print: Carlos Slebi-Acevedo, Pablo Lastra-González, Pablo Pascual-Muñoz, Daniel Castro-Fresno. “Mechanical performance of fibers in hot mix asphalt: a review". Construction and Building Materials 200 (2019), 756-769. ISSN 09500618. DOI: 10.1016/j.conbuildmat.2018.12.171

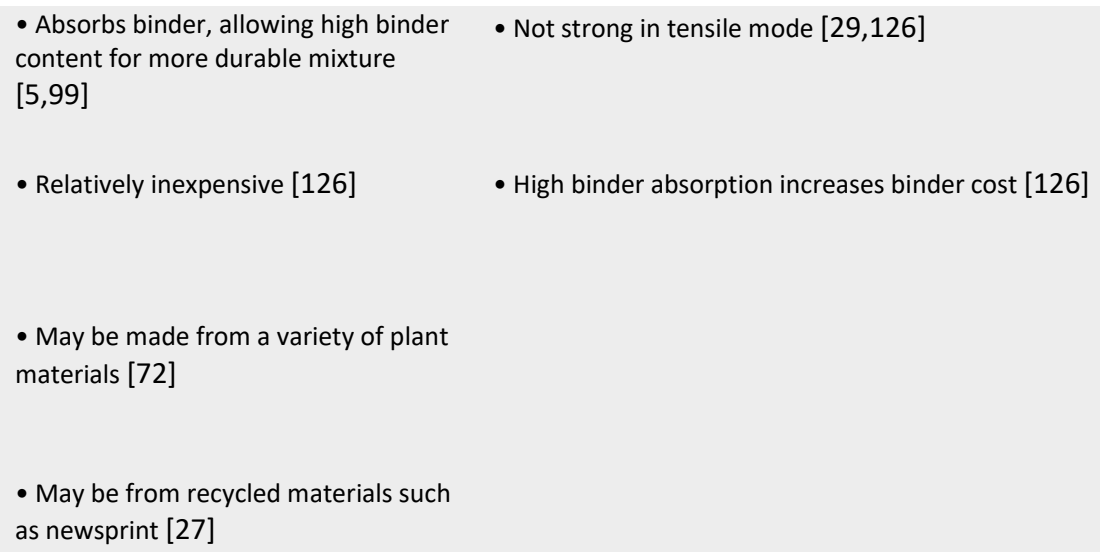

\subsection{Use of waste fibers for the reinforcement of asphalt mixtures}

570 Several industries, during their manufacturing process, generate waste fibers that are usually 571 dumped in landfills. However, these fibers can be used for the design of fiber-reinforced asphalt 572 mixtures. Putman and Amirkhanian [27] implemented the use in SMA mixtures of tire and carpet 573 fibers coming from scrap tires and automotive carpet manufacturing, respectively. As confirmed 574 by the results, the toughness increased compared to mixtures with cellulose fibers. A decrease 575 in the optimum binder content was noticed by the authors in SMA mixtures with cellulose fibers 576 when $0.1 \%$ and $0.45 \%$ waste tire and carpet fibers, respectively, were added, thus resulting in a 577 more cost effective asphalt mixture.

578 Nylon wires from the production of products such as toothbrushes, hairbrushes or paintbrushes 579 have been recycled and used for the manufacturing of SMA mixes. An optimal content between $5801 \%$ and $1.5 \%$ by weight of asphalt mixture enhances high-temperature stability, resistance to 581 low-temperature cracking and moisture susceptibility [26]. This waste fiber provides a bridging effect in the mixture that minimizes crack propagation [78].

583 Inadequate disposal of metal waste can become an environmental problem. In fact, when disposed of in landfills, these pollutants can reach the soil and water of wetlands and affect ecosystems [141]. In 2014, a waste production of 2.5 billion tons was reported, of which 99.7 million correspond to metallic waste [142]. Therefore, the use of waste metallic fibers has become an environmentally friendly option for the manufacturing of fiber-reinforced asphalt mixtures. Thus, the use of steel wool fibers and metal shavings in asphalt mixtures has resulted in a good performance, including mechanical response, durability and electrical conductivity [116]. Ajam et al. [143] suggest the use of metal shavings in surface layers.

The use in SMA mixtures of waste synthetic fibers (acrylic-polyester) and waste cellulose fibers from the automotive carpet manufacturing process was investigated by Moghaddam et al. 593 [144]. In this research, Marshall stability, compressive strength, tensile strength, drain down and moisture susceptibility tests were carried out. Waste cellulose fibers provided the best results in terms of binder content stabilization. On the other hand, waste synthetic fibers performed better in terms of moisture resistance and toughness. 
Author's post-print: Carlos Slebi-Acevedo, Pablo Lastra-González, Pablo Pascual-Muñoz, Daniel Castro-Fresno. “Mechanical performance of fibers in hot mix asphalt: a review". Construction and Building Materials 200 (2019), 756-769. ISSN 09500618. DOI: 10.1016/j.conbuildmat.2018.12.171

597 Valeri et al. [145] studied the effect of adding tetra-pack material in porous asphalt mixtures. 598 This material is made up of $63 \%$ cellulose and $30 \%$ Low-Density Polyethylene (LDPE). Results of 599 mechanical performance indicated that tetra-pack fibers produced similar or even greater 600 improvement than conventional cellulose fibers in PA mixtures. Tetra-pack fibers $(0.25-0.50 \%$ 601 by weight of mixture) provided remarkable mechanical properties without decreasing the permeability of the PA mixture. In an overall sense, it can be said that regardless of the fact that they are waste fibers, they maintain their mechcanical properties and contribute to better performance of asphalt mixtures, while providing an environmentally friendly solution. 
Author's post-print: Carlos Slebi-Acevedo, Pablo Lastra-González, Pablo Pascual-Muñoz, Daniel Castro-Fresno. "Mechanical performance of fibers in hot mix asphalt: a review". Construction and Building Materials 200 (2019), 756-769. ISSN 0950-0618. DOI: 10.1016/j.conbuildmat.2018.12.171

Table 9 Specifications and greatest improvements of different types of fibers used in HMA

\begin{tabular}{|c|c|c|c|c|c|c|c|c|c|c|c|c|c|c|c|c|c|c|c|}
\hline \multicolumn{9}{|c|}{ Fiber characteristics } & \multicolumn{11}{|c|}{ Maximum improvement } \\
\hline Citation & Fibers & $\begin{array}{l}\text { Length } \\
(\mathrm{mm})\end{array}$ & $\begin{array}{c}\text { Diameter } \\
(\mathrm{mm})\end{array}$ & $\begin{array}{l}\text { Density } \\
\left(\mathrm{g} / \mathrm{cm}^{3}\right)\end{array}$ & $\begin{array}{c}\text { Fiber content } \\
\text { by weight of } \\
\text { mixture }\end{array}$ & $\begin{array}{c}\text { Tensile } \\
\text { Strength } \\
\text { (Mpa) }\end{array}$ & $\begin{array}{l}\text { Elastic } \\
\text { modulus } \\
\text { (Mpa) }\end{array}$ & $\begin{array}{l}\text { Softening } \\
\text { point }\left({ }^{\circ} \mathrm{C}\right)\end{array}$ & Rutting & $\mathrm{MS}^{\mathrm{b}}$ & $\mathrm{MF}^{\mathrm{c}}$ & Toughness & $\begin{array}{c}\text { Moisture } \\
\text { susceptibility }\end{array}$ & $\begin{array}{l}\text { Fatigue } \\
\text { life }\end{array}$ & $\mathrm{ITS}^{\mathrm{d}}$ & $\mathrm{FE}^{\mathrm{e}}$ & $\begin{array}{l}\text { Dynamic } \\
\text { stability }\end{array}$ & $\begin{array}{c}\text { Complex } \\
\text { modulus } \\
\mathrm{E}^{*}\end{array}$ & $\begin{array}{l}\text { Resilient } \\
\text { modulus }\end{array}$ \\
\hline \multirow[b]{2}{*}{ [111] } & Macro glass & 36 & 0.54 & 2.68 & $0.40 \%$ & 1700 & 72000 & 860 & $47 \%$ & $1 \%$ & $23 \%$ & $24 \%$ & & & & & & & \\
\hline & Micro glass & 25 & 0.21 & 2.68 & $0.40 \%$ & & & 860 & $25 \%$ & & & & & & & & & & \\
\hline \multirow[t]{2}{*}{ [83] } & Aramid & 19 & & 1.45 & $0.05 \%$ & 3000 & 83000 & $>450$ & & & & $32 \%$ & $20 \%$ & $20 \%$ & $21 \%$ & & & $30 \%$ & $15 \%$ \\
\hline & Polyester & 6 & 0.02 & & $0.30 \%$ & 531 & & & $19.57 \%$ & & & $43.52 \%$ & & $57.66 \%$ & & $46.15 \%$ & & & \\
\hline \multirow{3}{*}[146]{} & Polyacrilonitrile & $\begin{array}{l}4.00- \\
6.00\end{array}$ & $N / A^{a}$ & & $0.30 \%$ & $>910$ & & & $32.56 \%$ & & & $61.11 \%$ & & $66.78 \%$ & & $26.92 \%$ & & & \\
\hline & Lignin & 1.1 & 0.045 & & $0.30 \%$ & $N / A^{a}$ & & & $8.43 \%$ & & & $12.03 \%$ & & $40.88 \%$ & & $0 \%$ & & & \\
\hline & Asbestos & 5.5 & $N / A^{a}$ & & $0.30 \%$ & $30-40$ & & & $11.40 \%$ & & & $28.71 \%$ & & $22.52 \%$ & & $34.61 \%$ & & & \\
\hline \multirow{2}{*}[147]{} & Hooked steel & 30 & 0.4 & & $5 \%$ & 1345 & 210000 & & & & & $727 \%$ & & & $63 \%$ & $286 \%$ & & & \\
\hline & Twisted steel & 30 & 0.3 & & $5 \%$ & 1345 & 210000 & & & & & $896 \%$ & & & $56 \%$ & $370 \%$ & & & \\
\hline \multirow[t]{3}{*}{ [72] } & Coconut & & & 1.18 & $0.30 \%$ & 118 & 2800 & & & & & & & & & & & & $8.79 \%$ \\
\hline & Polypropylene & 6 & 0.04 & 0.91 & $1.0 \% \mathrm{f}$ & 500 & 3500 & 160 & $27.50 \%$ & $\begin{array}{c}11.50 \%- \\
0 \%\end{array}$ & $11.43 \%$ & & & & $2.35 \%$ & & & & \\
\hline & Polyester & 6 & 0.041 & 1.4 & $1.0 \% \mathrm{f}$ & 1147 & 11600 & 256 & & $15.30 \%$ & $14.28 \%$ & & & & & & $62.70 \%$ & & \\
\hline \multirow[t]{3}{*}{ [132] } & Nylon & 12 & 0.023 & 1.14 & $1.0 \% \mathrm{f}$ & 800 & $\begin{array}{l}3500- \\
7000\end{array}$ & 220 & & $8.10 \%$ & $2.53 \%$ & $158 \%$ & & & & & $51.00 \%$ & & \\
\hline & Carbon & 12 & 0.007 & 1.37 & $1.0 \% \mathrm{f}$ & 4900 & 230000 & $\begin{array}{l}\text { over } \\
1000\end{array}$ & & $0.88 \%$ & & $12.10 \%$ & & & & & & & \\
\hline & Polyester & 6 & & 1.4 & $0.35 \%$ & & & & & & & & & & $15 \%$ & & & & \\
\hline [97] & Polyester & 13 & & 1.4 & $0.50 \%$ & & & & & & & $117 \%$ & & & & & & & \\
\hline [26] & $\begin{array}{l}\text { Waste nylon } \\
\text { wire }\end{array}$ & 20 & 0.2 & 1.11 & $1 \%$ & 357 & & 220 & & $23 \%$ & & & $9.02 \%$ & & $14.89 \%$ & & & & \\
\hline$[125]$ & Basalt & & $0.01-0.019$ & 2.67 & $0.30 \%$ & & 84000 & 1350 & $33.30 \%$ & & & & & & & & & & \\
\hline [46] & Carbon & 5 & 0.01 & & $2 \%^{f}$ & 1680 & 752000 & & $2.56 \%$ & $5.47 \%$ & $14.65 \%$ & & & & & & & & $2.86 \%$ \\
\hline [99] & Polyacrylonitrile & 6 & 0.0013 & 1.18 & $2 \%$ & & $>910$ & 240 & $45.96 \%$ & & & & & & & & & & \\
\hline$[148]$ & $\begin{array}{l}\text { Waste } \\
\text { polyester }\end{array}$ & 13 & & & $0.50 \%$ & 680 & & 265 & & & $80 \%$ & & & $31 \%$ & & & & & \\
\hline [12] & Waste cellulose & $\begin{array}{l}0.5- \\
2.00\end{array}$ & & $\begin{array}{l}0.52- \\
0.56\end{array}$ & $0.50 \%$ & & & & & & & & & & $22 \%$ & & & & \\
\hline & & & & & & & & & 22 & & & & & & & & & & \\
\hline
\end{tabular}


Author's post-print: Carlos Slebi-Acevedo, Pablo Lastra-González, Pablo Pascual-Muñoz, Daniel Castro-Fresno. "Mechanical performance of fibers in hot mix asphalt: a review". Construction and Building Materials 200 (2019), 756-769. ISSN 0950-0618. DOI: 10.1016/j.conbuildmat.2018.12.171

\begin{tabular}{|c|c|c|c|c|c|c|c|c|c|c|c|c|c|}
\hline [78] & Nylon & & 12 & & $1.00 \%$ & & & & $85 \%$ & & & & \\
\hline \multirow{2}{*}{ [149] } & \multirow{2}{*}{$\begin{array}{l}\text { Polyolefin + } \\
\text { aramid }\end{array}$} & 19 & & 0.91 & $0.05 \%$ & 483 & 130 & $17 \%$ & & \multirow[t]{2}{*}{$11 \%$} & & & \multirow[t]{2}{*}{$31 \%$} \\
\hline & & 19 & & 1.45 & & 2750 & 450 & & & & & & \\
\hline [137] & Aramid & 19 & 0.012 & & $0.07 \%$ & 2700 & 426 & $139 \%$ & & & & & \\
\hline \multirow{2}{*}{ [119] } & \multirow{2}{*}{$\begin{array}{l}\text { Polypropylene + } \\
\text { Aramid }\end{array}$} & 19 & & 0.91 & - & 483 & 157 & & & \multirow{2}{*}{$\begin{array}{l}25- \\
50 \%\end{array}$} & \multirow{2}{*}{$\begin{array}{l}50- \\
75 \%\end{array}$} & \multirow[t]{2}{*}{$20-50 \%^{8}$} & \\
\hline & & 19 & & 1.45 & - & 3000 & $>450$ & & & & & & \\
\hline
\end{tabular}

a. Not available
b. Marshall Stability

c. Marshall flow

d. Indirect Tensile Strength

e. Fracture Energy

f. Dosage made by volume

g. Depending on the temperature of the test 
Author's post-print: Carlos Slebi-Acevedo, Pablo Lastra-González, Pablo Pascual-Muñoz, Daniel Castro-Fresno. “Mechanical performance of fibers in hot mix asphalt: a review". Construction and Building Materials 200 (2019), 756-769. ISSN 09500618. DOI: 10.1016/j.conbuildmat.2018.12.171

608

609

610

611

612

613

614

615

616

617

618

619

620

621

622

623

624

625

626

627

628

629

630

631

632

633

634

635

636

637

638

639

640

641

642

643

644

645

646

647

648

649

650

\section{Conclusions}

In this paper, the different properties of fibers, their characteristic tests, the results of these tests and the impact that these fibers have on bituminous mixtures, have been carefully summarized. The most relevant conclusions are described next:

- The most relevant physical properties to be considered for proper analysis of the fibers are: tensile strength, modulus of elasticity, specific gravity and Mohs hardness. These features have a direct influence on the binder and the mixture performance.

- The interconnection generated between aggregates and fibers allows the material to withstand additional strain energy before cracking occurs. This is of great significance for providing long-life, safe pavements.

- The microstructure of the fibers, the pore content of their surfaces and their rigidities will affect the behavior of the bitumen and the mixture. The formation of fiber clusters must be avoided and uniform distribution must be achieved.

- In general, the incorporation of fibers into the bitumen increases its viscosity and softening point and reduces its penetration grade. The optimum content of fibers in the bitumen should be considered in order to achieve good workability and optimal properties.

- The most suitable tests to evaluate the asphalt binder performance at medium and high temperatures are the cone penetration test and DSR. For low temperatures, the tests that should be carried out are the BBR test, pullout test and direct tensile test.

- At low temperatures, bitumen tends to become fragile. The incorporation of fibers would work as a bridge, preventing the propagation of cracks and therefore, providing ductility to the binder.

- When using fibers, the binder content is increased because several of its light components are absorbed by the fibers. Therefore, fiber-reinforced asphalt mixtures have a higher optimum asphalt content compared to conventional asphalt mixtures.

- In general, all the fibers considered in this paper contribute to the enhancement of the mechanical properties of mixtures. The optimum fiber content is not the only variable to be considered; the fiber length also influences the mixture performance.

- Coconut fibers are natural fibers that do not require a manufacturing process for their use in bituminous mixtures. They can be considered an environmentally friendly substitute for synthetic fibers .

- The use of waste fibers in asphalt mixtures has contributed to their good performance. cost savings in the manufacturing of the mixes and environmental benefits should also be observed.

As future research, the study of the assessment and prediction of the orientation and distribution of fibers in bituminous binders and asphalt mixtures is recommended. Moreover, very little information is available regarding the use of fibers in porous mixtures. Additionally, some fibers improve some characteristics more than others (e.g., some of them would influence the binder performance), whereas others would be focused on improving the mechanical performance. Thus, the evaluation of the combination of fibers in different mixtures is also recommended as future research. Finally, the application of principles of composite science to model the fiber reinforcement effect in HMA should also be considered. 
Author's post-print: Carlos Slebi-Acevedo, Pablo Lastra-González, Pablo Pascual-Muñoz, Daniel Castro-Fresno. “Mechanical performance of fibers in hot mix asphalt: a review". Construction and Building Materials 200 (2019), 756-769. ISSN 09500618. DOI: 10.1016/j.conbuildmat.2018.12.171

651

652

653

654

655

656

657

658

659

660

661

662

663

664

665

666

667

668

669

670

671

672

673

674

675

676

677

678

679

680

681

682

683

684

685

\section{Acknowledgement}

This work has received funding from the CEDR Transnational Road Research Programme - call 2017 under the contract N. 867481, "Fostering the implementation of fiber-reinforced asphalt mixtures by ensuring its safe, optimized and cost-efficient use (FIBRA)". The authors wish to express their gratitude to the reviewers for the comments that greatly improved this manuscript.

\section{References}

[1] F. Frigio, S. Raschia, D. Steiner, B. Hofko, F. Canestrari, Aging effects on recycled WMA porous asphalt mixtures, Constr. Build. Mater. 123 (2016) 712-718. doi:10.1016/j.conbuildmat.2016.07.063.

[2] H. Chen, Q. Xu, Experimental study of fibers in stabilizing and reinforcing asphalt binder, Fuel. (2010). doi:10.1016/j.fuel.2009.08.020.

[3] B. Golestani, B.H. Nam, F. Moghadas Nejad, S. Fallah, Nanoclay application to asphalt concrete: Characterization of polymer and linear nanocomposite-modified asphalt binder and mixture, Constr. Build. Mater. 91 (2015) 32-38. doi:10.1016/j.conbuildmat.2015.05.019.

[4] R. Xiong, J. Fang, A. Xu, B. Guan, Z. Liu, Laboratory investigation on the brucite fiber reinforced asphalt binder and asphalt concrete, Constr. Build. Mater. 83 (2015) 44-52. doi:10.1016/j.conbuildmat.2015.02.089.

[5] M. Mohammed, T. Parry, J. (J R.A.). Grenfell, Influence of fibres on rheological properties and toughness of bituminous binder, Constr. Build. Mater. 163 (2018) 901-911. doi:10.1016/j.conbuildmat.2017.12.146.

[6] R. Fitzgerald, Novel applications of carbon fiber for hot mix asphalt reinforcement and carbon - carbon pre forms, Michigan Technological University, 2000.

[7] J. Serfass, J. Samanos, Fiber-modified asphalt concrete characteristics, applications and behavior, .. J Assoc Asph. Paving Technol. 64 (1996) 193-230.

[8] Y.T. Al-Hadidy A, Mechanistic approach for polypropylene-modified flexible pavements., Mater. Des. 30 (2009) 1133-40.

[9] Al-Hadidy, T. Yi-qiu, Effect of polyethylene on life of flexible pavements., Constr. Build. Mater. 23 (2009) 1456-64.

[10] A. Mokhtari, M. Nejad, Fereidoon, Mechanistic approach for fiber and polymer modified SMA mixtures, Constr. Build. Mater. $36 \quad$ (2012) 381-390. doi:10.1016/j.conbuildmat.2012.05.032.

[11] H.F. Hassan, K.S. Al-Jabri, Effect of organic fibers on open-graded friction course mixture properties, Int. J. Pavement Eng. 6 (2005) 67-75. doi:10.1080/10298430500087936. 
Author's post-print: Carlos Slebi-Acevedo, Pablo Lastra-González, Pablo Pascual-Muñoz, Daniel Castro-Fresno. “Mechanical performance of fibers in hot mix asphalt: a review". Construction and Building Materials 200 (2019), 756-769. ISSN 09500618. DOI: 10.1016/j.conbuildmat.2018.12.171

686

687

688

689

690

691

692

693

694

695

696

697

698

699

700

701

702

703

704

705

706

707

708

709

710

711

712

713

714

716

[12] V.C. Andrés-Valeri, J. Rodriguez-Torres, M.A. Calzada-Perez, J. Rodriguez-Hernandez, Exploratory study of porous asphalt mixtures with additions of reclaimed tetra pak material, Constr. Build. Mater. $160 \quad$ (2018) 233-239. doi:10.1016/j.conbuildmat.2017.11.067.

[13] S. Jahromi, A. Khodaii, Carbon Fiber Reinforced Asphalt Concrete, Arab. J. Sci. Eng. 33 (2008) 355-364.

[14] Z. Salari, B. Vakhshouri, S. Nejadi, Analytical review of the mix design of fiber reinforced high strength selfcompacting concrete, J. Build. Eng. 20 (2018) 264-276.

[15] C.Elanchezhiana, B.V. Ramnathb, G.Ramakrishnanc, M.Rajendrakumard, V.Naveenkumare, M.K.Saravanakumarf, Review on mechanical properties of natural fiber composites., Materials (Basel). 5 (2018) 1785-1790.

[16] M. Sood, G. Dwivedi, Effect of fiber treatment on flexural properties of natural fiber reinforced composites: A review, Egypt. J. Pet. (2018). doi:10.1016/j.ejpe.2017.11.005.

[17] F. Roberts, P. Kandhal, Hot Mix Asphalt Materials, Mixture Design, and Construction., Second, 1996.

[18] X. Qin, A. Shen, Y. Guo, Z. Li, Z. Lv, Characterization of asphalt mastics reinforced with basalt fibers, Constr. Build. Mater. 159 (2018) 508-516. doi:10.1016/j.conbuildmat.2017.11.012.

[19] S. Qian, H. Ma, J. Feng, R. Yang, X. Huang, Fiber reinforcing effect on asphalt binder under low temperature, Constr. Build. Mater. 61 (2014) 120-124. doi:10.1016/j.conbuildmat.2014.02.035.

[20] M.J. Khattak, A. Khattab, H.R. Rizvi, P. Zhang, The impact of carbon nano-fiber modification on asphalt binder rheology, Constr. Build. Mater. 30 (2012) 257-264. doi:10.1016/j.conbuildmat.2011.12.022.

[21] K.R. Lyons, B.J. Putman, Laboratory evaluation of stabilizing methods for porous asphalt mixtures, Constr. Build. Mater. $49 \quad$ (2013) 772-780. doi:10.1016/j.conbuildmat.2013.08.076.

[22] J. Tanzadeh, R. Shahrezagamasaei, Laboratory Assessment of Hybrid Fiber and Nanosilica on Reinforced Porous Asphalt Mixtures, Constr. Build. Mater. 144 (2017) 260-270. doi:10.1016/j.conbuildmat.2017.03.184.

[23] M.L. Afonso, M. Dinis-Almeida, C.S. Fael, Study of the porous asphalt performance with cellulosic fibres, Constr. Build. Mater. $135 \quad$ (2017) 104-111. doi:10.1016/j.conbuildmat.2016.12.222.

[24] S.M. Abtahi, M. Sheikhzadeh, S.M. Hejazi, Fiber-reinforced asphalt-concrete - A review, Constr. Build. Mater. 24 (2010) 871-877. doi:10.1016/j.conbuildmat.2009.11.009. 
Author's post-print: Carlos Slebi-Acevedo, Pablo Lastra-González, Pablo Pascual-Muñoz, Daniel Castro-Fresno. “Mechanical performance of fibers in hot mix asphalt: a review". Construction and Building Materials 200 (2019), 756-769. ISSN 09500618. DOI: 10.1016/j.conbuildmat.2018.12.171

722

[25] B.J. Putman, S.N. Amirkhanian, Utilization of waste fibers in stone matrix asphalt mixtures, Resour. Conserv. Recycl. 42 (2004) 265-274.

[26] J.M. Yin, W. Wu, Utilization of waste nylon wire in stone matrix asphalt mixtures, Waste Manag. 78 (2018) 948-954. doi:10.1016/j.wasman.2018.06.055.

[27] B.J. Putman, S.N. Amirkhanian, Utilization of waste fibers in stone matrix asphalt mixtures, Resour. Conserv. Recycl. 42 (2004) 265-274. doi:10.1016/j.resconrec.2004.04.005.

[28] A. Mahrez, M. Karim, H. Katman, Fatigue and Deformation Properties of Glass Reinforced Bituminous Mixtures., East. Asia Soc. Transp. Stud. 6 (2005) 997-1007.

[29] J. Bijwe, Composites as friction materials: recent developments in non- asbestos fiber reinforced friction materials, 18 (1997) 378-396.

[30] U.B. Mohlin, B. Petterson, Improved Papermaking by Cellulase Treatment Before Refining, Prog. Biotechnol. 21 (2002) 291-299.

[31] B.S. Gupta, Manufacture, types and properties of biotextiles for medical applications, biotextiles as medical plants, 2013.

[32] Kauffman, B. George, Rayon: the first semi-synthetic fiber product"., J. Chem. Educ. 70 (1993) 887.

[33] G. J.E, The New Science of Strong Materials, Or, Why You Don't Fall Through the Floor, Princeton University press, 2006.

[34] D.J. Mundt, K.M. Marano, A.P. Nunes, R.C. Adams, A Review of Changes in Composition of Hot Mix Asphalt in the United States, J. Occup. Environ. Hyg. 6 (2009) 714-725. doi:10.1080/15459620903249125.

[35] J. Stempihar, M. Souliman, K. Kaloush, Fiber-Reinforced Asphalt Concrete as Sustainable Paving Material for Airfields, Transp. Res. Rec. J. Transp. Res. Board. 2266 (2012) 60-68. doi:10.3141/2266-07.

[36] R. Costa, R. Orriols, Man-Made Mineral Fibers and the Respiratory Tract, Arch. Bronconeumol. 48 (2012) 460-468.

[37] U. Larisaa, L. Solbona, B. Sergeib, Fiber-reinforced concrete with mineral fibers and nanosilica, Procedia Eng. 195 (2017) 147-154.

[38] B. SL, M. DM, B. BB, The mini plant producing thermal insulation materials from basalt on the basis of electromagnetic melting units with low energy consumption, Bull. East Sib. State Univ. Technol. Manag. 1 (2012) 16-20.

[39] J. Militký, Tensile failure of polyester fibers, in: Handb. Prop. Text. Tech. Fibres, Elsevier, 2018: pp. 421-514. doi:10.1016/B978-0-08-101272-7.00013-4. 
Author's post-print: Carlos Slebi-Acevedo, Pablo Lastra-González, Pablo Pascual-Muñoz, Daniel Castro-Fresno. “Mechanical performance of fibers in hot mix asphalt: a review". Construction and Building Materials 200 (2019), 756-769. ISSN 09500618. DOI: 10.1016/j.conbuildmat.2018.12.171

[40] S. Grishanov, Structure and properties of textile materials., in: Hnadb. Text. Ind. Dye., 2011.

[41] P. Morgan, Carbon Fibers and Their Composites, CRC Press, 2005. doi:10.1201/9781420028744.

[42] C.A.R. Brito, R.R. Fleming, L.C. Pardini, N.P. Alves, Empregados na Indústria, Polímeros Ciência e Tecnol. 23 (2013) 764-770. doi:10.4322/polimeros.2013.006.

[43] N. FASANELLA, MECHANICAL CHARACTERIZATION OF ADVANCED POLYACRYLONITRILE DERIVED CARBON FIBERS REINFORCED WITH CARBON NANOTUBES, University of Illinois at Urbana-Champaign, 2012.

[44] R.F. Ribeiro, L.C. Pardini, N.P. Alves, C.A.R. Brito Júnior, Thermal Stabilization study of polyacrylonitrile fiber obtained by extrusion, Polímeros. 25 (2015) 523-530. doi:10.1590/0104-1428.1938.

[45] P. Pan, S. Wu, F. Xiao, L. Pang, Y. Xiao, Conductive asphalt concrete: A review on structure design, performance, and practical applications, J. Intell. Mater. Syst. Struct. 26 (2015) 755-769. doi:10.1177/1045389X14530594.

[46] X. Liu, S. Wu, Study on the graphite and carbon fiber modified asphalt concrete, Constr. Build. Mater. 25 (2011) 1807-1811. doi:10.1016/j.conbuildmat.2010.11.082.

[47] Y. Agari, A. Ueda, S. Nagai, Thermal conductivity of a polyethylene filled with disoriented short-cut carbon fibers, J. Appl. Polym. Sci. 43 (1991) 1117-1124. doi:10.1002/app.1991.070430612.

[48] T. Tam, A. Bhatnagar, High-performance ballistic fibers and tapes, 2016. doi:10.1016/B978-0-08-100406-7.00001-5.

[49] H. Jamal, Manufacture, Properties and Design of Steel Fibers in Reinforced Concrete, n.d. https://www.aboutcivil.org/steel-fibers-reinforcing-concrete.html.

[50] Z. Cheng, L. Zhang, C. Jiang, Y. Dai, C. Meng, L. Luo, X. Liu?, Aramid fiber with excellent interfacial properties suitable for resin composite in a wide polarity range, Chem. Eng. J. 347 (2018) 483-492.

[51] B.A. Pattersona, M.H. Malakootib, J. Linc, A. Okoromd, H.A. Sodano, Aramid nanofibers for multiscale fiber reinforcement of polymer composites, Compos. Sci. Technol. 161 (2018) 92-99.

[52] O.S. Abiola, W.K. Kupolati, E.R. Sadiku, J.M. Ndambuki, Utilisation of natural fibre as modifier in bituminous mixes: A review, Constr. Build. Mater. 54 (2014) 305-312. doi:10.1016/j.conbuildmat.2013.12.037.

[53] S. Park, R.A. Venditti, H. Jameel, J.J. Pawlak, Changes in pore size distribution during the drying of cellulose fibers as measured by differential scanning calorimetry, Carbohydr. Polym. 66 (2006) 97-103. doi:10.1016/j.carbpol.2006.02.026. 
Author's post-print: Carlos Slebi-Acevedo, Pablo Lastra-González, Pablo Pascual-Muñoz, Daniel Castro-Fresno. “Mechanical performance of fibers in hot mix asphalt: a review". Construction and Building Materials 200 (2019), 756-769. ISSN 09500618. DOI: 10.1016/j.conbuildmat.2018.12.171

792

793

794

795

796

797

798

799

800

801

802

803

804

805

806

807

808

809

810

811

812

813

814

815

816

817

818

819

820

821

822

823

[54] B. Xu, J. Chen, M. Li, D. Cao, S. Ping, Y. Zhang, W. Wang, Experimental investigation of preventive maintenance materials of porous asphalt mixture based on high viscosity modified bitumen, Constr. Build. Mater. 124 (2016) 681-689. doi:10.1016/j.conbuildmat.2016.07.122.

[55] M. Mazumder, R. Ahmed, A.W. Ali, S.-J. Lee, SEM and ESEM techniques used for analysis of asphalt binder and mixture: A state of the art review, Constr. Build. Mater. 186 (2018) 313-329.

[56] Hortolá, Policarp, Evaluating the Use of Synthetic Replicas for SEM Identification of Bloodstains (with Emphasis on Archaeological and Ethnographic Artifacts), Microsc. Microanal. 21 (2015) 1504-1513. doi:10.1017/S1431927615014920.

[57] W. Meng Meng, L. Rui, Y.Z. Zhang, L. Fan, Y.C. Lv, J.M. Wei, Stabilizing and reinforcing effects of different fibers on asphalt mortar performance, Pet. Sci. 12 (2015) 189-196. doi:10.1007/s12182-014-0011-8.

[58] J. Wan, S. Wu, Y. Xiao, Q. Liu, E. Schlangen, Characteristics of Ceramic Fiber Modified Asphalt Mortar, Materials (Basel). 9 (2016) 788. doi:10.3390/ma9090788.

[59] C. Gao, W. Wu, Using ESEM to analyze the microscopic property of basalt fiber reinforced asphalt concrete, Int. J. Pavement Res. Technol. 11 (2018) 374-380. doi:10.1016/j.ijprt.2017.09.010.

[60] L. Sun, Q. Zhao, J. Xiang, J. Shi, L. Wang, S. Hu, S. Su, Adsorption of NO and NH3 over CuO/Y-Al2O3 catalyst by DRIFTS, Huagong Xuebao/CIESC J. 60 (2009) 444-449. doi:10.1007/s11771.

[61] M. Wu, R. Li, Y. Zhang, J. Wei, Y. Lv, X. Ding, Reinforcement effect of fiber and deoiled asphalt on high viscosity rubber/SBS modified asphalt mortar, Pet. Sci. 11 (2014) 454459. doi:10.1007/s12182-014-0361-2.

[62] A. Alrajhi, Fiber dosage effects in asphalt binders and hot asphalt mixtures, (2012).

[63] S. Fu, B. Lauke, E. Mader, Tensile properties of short-glass-fiber and short - carbon - fiber -reinforced polypropylene composites, Compos. Part A. 31 (2000) 1117-25.

[64] Y. Du, J. Chen, Z. Han, W. Liu, A review on solutions for improving rutting resistance of asphalt pavement and test methods, Constr. Build. Mater. 168 (2018) 893-905. doi:10.1016/j.conbuildmat.2018.02.151.

[65] ASTM D7175-15, Standard test method for determining the rheological properties of asphalt binder using a dynamic shear rheometer. ASTM International, West Conshohocken, PA, 2015., (n.d.).

[66] R. Xiong, L. Wang, X. Yang, F. Yang, Y. Sheng, B. Guan, H. Chen, Experimental investigation on related properties of asphalt mastic with activated coal gangue as alternative filler, Int. J. Pavement Res. Technol. (2018). doi:10.1016/j.ijprt.2018.03.002. 
Author's post-print: Carlos Slebi-Acevedo, Pablo Lastra-González, Pablo Pascual-Muñoz, Daniel Castro-Fresno. “Mechanical performance of fibers in hot mix asphalt: a review". Construction and Building Materials 200 (2019), 756-769. ISSN 09500618. DOI: 10.1016/j.conbuildmat.2018.12.171

828

829

830

831

832

833

834

835

836

837

838

839

840

841

842

843

844

845

846

847

848

849

850

851

852

853

854

855

856

857

[67] P. Kumar, R. Garg, Rheology of waste plastic fibre-modified bitumen, Int. J. Pavement Eng. 12 (2011) 449-459. doi:10.1080/10298430903255296.

[68] S. Wu, Z. Chen, Q. Ye, W. Liao, Effects of fibre additive on the high temperature property of asphalt binder, J. Wuhan Univ. Technol. Mater. Sci. Ed. 21 (2006) 118-120. doi:10.1007/BF02861487.

[69] J.S. Chen, K.Y.I. Lin, Mechanism and behavior of bitumen strength reinforcement using fibers, J. Mater. Sci. 40 (2005) 87-95. doi:10.1007/s10853-005-5691-4.

[70] V.C. Li, H. Stang, Interface property characterization and strengthening mechanisms in fiber reinforced cement based composites, Adv. Cem. Based Mater. 6 (1997) 1-20. doi:10.1016/S1065-7355(97)90001-8.

[71] Q. Liu, S. Wu, C. Liu, J. Wang, Investigation of rheological properties of TPS modified bitumen, J. Cent. South Univ. Technol. 15 (2008) 118-121. doi:10.1007/s11771-0080328-9.

[72] S. Oda, J. Leomar Fernandes, J.S. Ildefonso, Analysis of use of natural fibers and asphalt rubber binder in discontinuous asphalt mixtures, Constr. Build. Mater. 26 (2012) 13-20. doi:10.1016/j.conbuildmat.2011.06.030.

[73] AASHTO T 305 - Standard Method of Test for Determination of Draindown Characteristics in Uncompacted Asphalt Mixtures, (n.d.).

[74] H. Chen, Q. Xu, S. Chen, Z. Zhang, Evaluation and design of fiber-reinforced asphalt mixtures, Mater. Des. 30 (2009) 2595-2603. doi:10.1016/j.matdes.2008.09.030.

[75] Putman, S.N., Amirkhanian, Utilization of waste fibers in stone matrix asphalt mixtures, Resour, Conserv -Recycl. 42 (2004) 265-274.

[76] P. Peltonen, Wear and deformation characteristics of fibre reinforced asphalt pavements, Constr. Build. Mater. 5 (1991) 18-22. doi:10.1016/0950-0618(91)90027-I.

[77] E.A.P. Association, European Asphalt Pavement Association, (2015). www.EAPA.org/userfiles/2/Asphalt/ in figures/2014/AlF_2014_v10.pdf.

[78] S.J. Lee, J.P. Rust, H. Hamouda, Y.R. Kim, R.H. Borden, Fatigue Cracking Resistance of Fiber-Reinforced Asphalt Concrete, Text. Res. J. 75 (2005) 123-128. doi:10.1177/004051750507500206.

[79] S. Tapkın, Ü. Uşar, A. Tuncan, M. Tuncan, Repeated Creep Behavior of Polypropylene Fiber-Reinforced Bituminous Mixtures, J. Transp. Eng. 135 (2009) 240-249. doi:10.1061/(ASCE)0733-947X(2009)135:4(240).

[80] Y. Tang, E. Haddock, Investigation of the performance of neat and modified asphalt binders, Jt. Transp. Res. Program. (n.d.). 
Author's post-print: Carlos Slebi-Acevedo, Pablo Lastra-González, Pablo Pascual-Muñoz, Daniel Castro-Fresno. “Mechanical performance of fibers in hot mix asphalt: a review". Construction and Building Materials 200 (2019), 756-769. ISSN 09500618. DOI: 10.1016/j.conbuildmat.2018.12.171

863

864

865

866

867

868

869

870

871

872

873

874

875

876

877

878

879

880

881

882

883

884

885

886

887

888

889

890

891

892

[81] J.. Echols, NEW MIX METHOD FOR FIBER-REINFORCED ASPHALT, Public Work. 119 (1989) 72-73. http://www.pwmag.com.

[82] H. SM., Mechanical reinforcement of hot mix asphalt using textile materials., Isfahan University of Technology, 2007.

[83] L.M.G. Klinsky, K.E. Kaloush, V.C. Faria, V.S.S. Bardini, Performance characteristics of fiber modified hot mix asphalt, Constr. Build. Mater. $176 \quad$ (2018) 747-752. doi:10.1016/j.conbuildmat.2018.04.221.

[84] A. García, J. Norambuena-Contreras, M.N. Partl, A parametric study on the influence of steel wool fibers in dense asphalt concrete, Mater. Struct. Constr. 47 (2014) 1559-1571. doi:10.1617/s11527-013-0135-0.

[85] D. Wo, Comprehensive composite materials, Chemistry, Beijing, China, 2000.

[86] G. White, State of the art: Asphalt for airport pavement surfacing, Int. J. Pavement Res. Technol. 11 (2018) 77-98. doi:10.1016/j.ijprt.2017.07.008.

[87] R. Mirzanamadi, P. Johansson, S.A. Grammatikos, Thermal properties of asphalt concrete: A numerical and experimental study, Constr. Build. Mater. 158 (2018) 774-785. doi:10.1016/j.conbuildmat.2017.10.068.

[88] R. Imaninasab, B. Bakhshi, B. Shirini, Rutting performance of rubberized porous asphalt using Finite Element Method (FEM), Constr. Build. Mater. 106 (2016) 382-391. doi:10.1016/j.conbuildmat.2015.12.134.

[89] V.S. Punith, A. Veeraragavan, Characterization of OGFC Mixtures Containing Reclaimed Polyethylene Fibers, J. Mater. Civ. Eng. 23 (2011) 335-341. doi:10.1061/(ASCE)MT.19435533.0000162.

[90] J. Tanzadeh, R. Shahrezagamasaei, Laboratory Assessment of Hybrid Fiber and Nanosilica on Reinforced Porous Asphalt Mixtures, Constr. Build. Mater. 144 (2017) 260-270.

[91] H.B. Chen X, Evaluation of moisture damage in hot mix asphalt using simple performance and superpave indirect tensile tests., Constr. Build. Mater. 22 (2008) 1950-62.

[92] X. Zhang, X. Gu, J. Lv, Z. Zhu, X. Zou, Numerical analysis of the rheological behaviors of basalt fiber reinforced asphalt mortar using ABAQUS, Constr. Build. Mater. 157 (2017) 392-401. doi:10.1016/j.conbuildmat.2017.09.044.

[93] G. Wu, D. Yang, Y. Wang, The influence of mixing methods on the mechanical and physical properties of polyester fiber-reinforced asphalt concrete, Proc. 6th Int. Spec. Conf. Fibre Reinf. Mater. (2017) 365-370.

[94] C. Toney, Fiber reinforced asphalt concrete pavements - city of Tacoma final report, Olympia, WA Washingt. State Transp. Comm. Dep. Transp. WA-RD 133. (1987). 
Author's post-print: Carlos Slebi-Acevedo, Pablo Lastra-González, Pablo Pascual-Muñoz, Daniel Castro-Fresno. “Mechanical performance of fibers in hot mix asphalt: a review". Construction and Building Materials 200 (2019), 756-769. ISSN 09500618. DOI: 10.1016/j.conbuildmat.2018.12.171

898

899

900

901

902

903

904

905

906

907

908

909

910

911

912

913

914

915

916

917

918

919

920

921

922

923

924

925

[95] D.A. Maurer, G.J. Malasheskie, Field performance of fabrics and fibers to retard reflective cracking, Geotext. Geomembranes. 8 (1989) 239-267. doi:10.1016/02661144(89)90005-8.

[96] S. Wu, Q. Ye, N. Li, Investigation of rheological and fatigue properties of asphalt mixtures containing polyester fibers, Constr. Build. Mater. 22 (2008) 2111-2115.

[97] R.B. Freeman, J.L. Burati, S.N. Amirkhanian, W.C. Bridges, Polyester fibers in asphalt paving mixtures, Assoc. Asph. Paving Technol. 58 (1989) 387-409.

[98] K.W. Kim, Y.S. Doh, S. Lim, Mode I reflection cracking resistance of strengthened asphalt concretes, Constr. Build. Mater. 13 (1999) 243-251. doi:10.1016/S0950-0618(99)00032$\mathrm{X}$.

[99] L. Yao, Y. Hu, Q. Ma, X. Ma, Stability of asphalt binder and asphalt mixture modified by polyacrylonitrile fibers, Adv. Mater. Res. 228-229 (2011) 242-247. doi:10.4028/www.scientific.net/AMR.228-229.242.

[100] X. Liu, W. Liu, S. Wu, C. Wang, Effect of carbon fillers on electrical and road properties of conductive asphalt materials, Constr. Build. Mater. 68 (2014) 301-306. doi:10.1016/j.conbuildmat.2014.06.059.

[101] S.G. Jahromi, Effect of Carbon Nanofiber on Mechanical Behavior of Asphalt Concrete, Int. J. Sustain. Constr. Eng. Technol. 6 (2015).

[102] Z. Yang, Y. Zhang, X. Shi, Impact of nanoclay and carbon microfiber in combating the deterioration of asphalt concrete by non-chloride deicers, Constr. Build. Mater. 160 (2018) 514-525.

[103] M.-J. Kim, S. Kim, D.-Y. Yoo, H.-O. Shin, Enhancing mechanical properties of asphalt concrete using synthetic fibers, Constr. Build. Mater. 178 (2018) 233-243.

[104] M. Zhang, C. Fang, S. Zhou, Y. Cheng, J. Hu, Modification of asphalt by dispersing waste polyethylene and carbon fibers in it, NEW CARBON Mater. 31 (2016) 424-430.

[105] M.. Cleven, Investigation of the Properties of Carbon Fiber Modified Asphalt Mixtures, Michigan Technological University Houghton, 2000.

[106] Q. Yuehong, W. Fan, G. Nan, Free-standing, binder-free polyacrylonitrile/asphalt derived porous carbon fiber - A high capacity anode material for sodium-ion batteries, Mater. Lett. 189 (2017) 206-209.

[107] Z. Wang, Q. Dai, D. Porter, Zhanping You, Investigation of microwave healing performance of electrically conductive carbon fiber modified asphalt mixture beams, Constr. Build. Mater. 126 (2016) 1012-1019.

[108] H. Wang, J. Yang, H. Liao, X. Chen, Electrical and mechanical properties of asphalt concrete containing conductive fibers and fillers, Constr. Build. Mater. 122 (2016) 184190. 
Author's post-print: Carlos Slebi-Acevedo, Pablo Lastra-González, Pablo Pascual-Muñoz, Daniel Castro-Fresno. “Mechanical performance of fibers in hot mix asphalt: a review". Construction and Building Materials 200 (2019), 756-769. ISSN 09500618. DOI: 10.1016/j.conbuildmat.2018.12.171

[109] A. Mahrez, Prospect of Using Glass Fiber Reinforced Bituminous, J. Eastren Asia Soc. Transp. Stud. 5 (2003) 794-807.

[110] A. MAHREZ, M.R. KARIM, H.Y. KATMAN, Fatigue and Deformation Properties of Glass Fiber Reinforced Bituminous Mixes, J. East. Asia Soc. Transp. Stud. 6 (2005) 997-1007. doi:10.1.1.567.9496.

[111] F. Morea, R. Zerbino, Improvement of asphalt mixture performance with glass macrofibers, Constr. Build. Mater. 164 (2018) 113-120.

[112] Q. Guo, L. Li, Y. Cheng, Y. Jiao, C. Xu, Laboratory evaluation on performance of diatomite and glass fiber compound modified asphalt mixture, Mater. Des. 66 (2015) 51-59.

[113] L. Minsk, Electrically conductive asphalt for control of snow and ice accumulation, Highw. Res. Board. 227 (n.d.) 57-63.

[114] Q. Liu, E. Schlangen, M. Van De Ven, G. Van Bochove, J. Van Montfort, Evaluation of the induction healing effect of porous asphalt concrete through four point bending fatigue test, Constr. Build. Mater. 29 (2012) 403-409. doi:10.1016/j.conbuildmat.2011.10.058.

[115] P. Park, S. El-Tawil, S.Y. Park, A.E. Naaman, Cracking resistance of fiber reinforced asphalt concrete at $-20{ }^{\circ} \mathrm{C}$, Constr. Build. Mater. $81 \quad$ (2015) 47-57. doi:10.1016/j.conbuildmat.2015.02.005.

[116] A. García, J. Norambuena-Contreras, M. Bueno, M.N. Partl, Single and multiple healing of porous and dense asphalt concrete, J. Intell. Mater. Syst. Struct. 26 (2015) 425-433. doi:10.1177/1045389X14529029.

[117] A. García, J. Norambuena-Contreras, M.N. Partl, P. Schuetz, Uniformity and mechanical properties of dense asphalt concrete with steel wool fibers, Constr. Build. Mater. 43 (2013) 107-117. doi:10.1016/j.conbuildmat.2013.01.030.

[118] Q. Liu, E. Schlangen, Á. García, M. van de Ven, Induction heating of electrically conductive porous asphalt concrete, Constr. Build. Mater. 24 (2010) 1207-1213. doi:10.1016/j.conbuildmat.2009.12.019.

[119] K. Kaloush, Evaluation of Fiber-Reinforced Asphalt Mixtures Using Advanced Material Characterization Tests, State, Arizona Univ. Dep. Civ. Environ. Eng. (2008).

[120] K. I E. Kaloush, Report of Evaluation FORTA Fiber-Reinforced Asphalt Mixtures Using Advanced Material Characterization Tests., Evergr. Drive, Tempe, Arizona. (2008).

[121] D.M. De Oliveira, M.O. Hilário Cioffi, K.C.C. De Carvalho Benini, H.J. Cornelis Voorwald, Effects of plasma treatment on the sorption properties of coconut fibers, Procedia Eng. 200 (2017) 357-364. doi:10.1016/j.proeng.2017.07.050.

[122] D.R. a. Mulinari, C.A.R.P.. Baptista, J.V.C.. Souza, H.J.C.. Voorwald, Mechanical Properties of Coconut Fibers Reinforced Polyester Composites, Procedia Eng. 10 (2011) 2074-2079. 
Author's post-print: Carlos Slebi-Acevedo, Pablo Lastra-González, Pablo Pascual-Muñoz, Daniel Castro-Fresno. “Mechanical performance of fibers in hot mix asphalt: a review". Construction and Building Materials 200 (2019), 756-769. ISSN 09500618. DOI: 10.1016/j.conbuildmat.2018.12.171

969

970

971

972

973

974

975

976

977

978

979

980

981

982

983

984

985

986

987

988

989

990

991

992

993

994

995

996

997

998

999

1000

1001

1002

[123] M. Panda, A. Suchismita, J. Giri, Utilization of Ripe Coconut Fiber in Stone Matrix Asphalt Mixes, Int. J. Transp. Sci. Technol. 2 (2013) 289-302. doi:10.1260/2046-0430.2.4.289.

[124] K. Thulsairajan, V. Narasimha, Studies on coir fibre reinforced bituminous concrete., Int J Earth Sci Eng. 04 (2011) 835-8.

[125] C. Celauro, F.G. Praticò, Asphalt mixtures modified with basalt fibres for surface courses, Constr. Build. Mater. 170 (2018) 245-253. doi:10.1016/j.conbuildmat.2018.03.058.

[126] R.S. McDaniel, Fiber additives in asphalt mixtures, (No. Proj. 20-05 (Topic 45-15)). (2015).

[127] Y. Xue, Z. Qian, Development and performance evaluation of epoxy asphalt concrete modified with mineral fiber, Constr. Build. Mater. 102 (2016) 378-383. doi:10.1016/j.conbuildmat.2015.10.157.

[128] P. Jenq, Y. S., Liaw, C. J., \& Lieu, Analysis of Crack Resistance of Asphalt Concrete Overlays-a Fracture Mechanics Approach., Transp. Res. Rec. 1388 (1993) 160-166.

[129] H. Zhu, J. Yang, L. Cong, J. Cui, J. Wan, Influence of polyester fibre on the performance of Asphalt mixes, Satc 2007.4 (2007) 118-126.

[130] X. Yu, L. Sun, Anti-cracking Ability of Asphalt Mixture Added with Polyester Fiber, Transportation (Amst). (2010) 656-666.

[131] C. Weise, A. Zeissler, Effects of fiber reinforcement on the fatigue and rutting performance of asphalt mixes, (2016).

[132] M.J. Kim, S. Kim, D.Y. Yoo, H.O. Shin, Enhancing mechanical properties of asphalt concrete using synthetic fibers, Constr. Build. Mater. 178 (2018) 233-243. doi:10.1016/j.conbuildmat.2018.05.070.

[133] M. Jamal Khattak, A. Khattab, H. R. Rizvi, Characterization of carbon nano-fiber modified hot mix asphalt mixtures, Constr. Build. Mater. 40 (2013) 738-745. doi:10.1016/j.conbuildmat.2012.11.034.

[134] M. Fakhri, S.A. Hosseini, Laboratory evaluation of rutting and moisture damage resistance of glass fiber modified warm mix asphalt incorporating high RAP proportion, Constr. Build. Mater. 134 (2017) 626-640. doi:10.1016/j.conbuildmat.2016.12.168.

[135] Y. Sun, S. Wu, Q. Liu, W. Zeng, Z. Chen, Q. Ye, P. Pan, Self-healing performance of asphalt mixtures through heating fibers or aggregate, Constr. Build. Mater. 150 (2017) 673-680. doi:10.1016/j.conbuildmat.2017.06.007.

[136] A. González, J. Norambuena-Contreras, L. Storey, E. Schlangen, Self-healing properties of recycled asphalt mixtures containing metal waste: An approach through microwave radiation heating, J. Environ. Manage. 214 (2018) 242-251. doi:10.1016/j.jenvman.2018.03.001. 
Author's post-print: Carlos Slebi-Acevedo, Pablo Lastra-González, Pablo Pascual-Muñoz, Daniel Castro-Fresno. “Mechanical performance of fibers in hot mix asphalt: a review". Construction and Building Materials 200 (2019), 756-769. ISSN 09500618. DOI: 10.1016/j.conbuildmat.2018.12.171

1004

1005

1006

1007

1008

1009

1010

1011

1012

1013

1014

1015

1016

1017

1018

1019

1020

1021

1022

1023

1024

1025

1026

1027

1028

1029

1030

1031

1032

1033

1034

1035

1036

1037

1038

[137] H. Noorvand, R. Salim, J. Medina, J. Stempihar, B.S. Underwood, Effect of Synthetic Fiber State on Mechanical Performance of Fiber Reinforced Asphalt Concrete, Transp. Res. Rec. J. Transp. Res. Board. (2018) 036119811878797. doi:10.1177/0361198118787975.

[138] M.R.M. Aliha, A. Razmi, A. Mansourian, The influence of natural and synthetic fibers on low temperature mixed mode I + II fracture behavior of warm mix asphalt (WMA) materials, Eng. Fract. Mech. $182 \quad$ (2017) 322-336. doi:10.1016/j.engfracmech.2017.06.003.

[139] N. P., Laboratory investigations on stone matrix asphalt using sisal fibre for Indian roads. BTech 2010, n.d.

[140] T. Krishnan, V.L. Narasimha, Studies on Coir Fibre Reinforced Bituminous Concrete, Int J Earth Sci Eng. 4 (n.d.).

[141] P.W. Abrahams, Soils: their implications to human health., Sci. Total Environ. 291 (2002) 1-32. doi:Doi: 10.1016/s0048-9697(01)01102-0.

[142] U.D. for Environment, F. and R. Affairs., UK statistics on Waste, 2016.

[143] B. Harith Ajam, I. Breixo Gomez-Meijide, I. Artamendi, A. Garcia, Mechanical and healing properties of asphalt mixes reinforced with different types of waste and commercial metal particles, J. Clean. Prod. 192 (2018) 138-150.

[144] A.M. Moghaddam, S.A. Ziaee, H.F. Mollashahi, Effects of Waste Fibers Stabilizers on the Draindown and Moisture Damage Sensitivity Properties of SMA Mixtures, Int. J. Transp. Eng. 2 (2014) 155-165.

[145] V.C. Andrés-Valeri, J. Rodriguez-Torres, M.A. Calzada-Perez, J. Rodriguez-Hernandez, Exploratory study of porous asphalt mixtures with additions of reclaimed tetra pak material, Constr. Build. Mater. 160 (2018) 233-239.

[146] Q. Xu, H. Chen, J.A. Prozzi, Performance of fiber reinforced asphalt concrete under environmental temperature and water effects, Constr. Build. Mater. 24 (2010) 20032010. doi:10.1016/j.conbuildmat.2010.03.012.

[147] P. Park, S. El-Tawil, S.-Y. Park, A.E. Naaman, Cracking resistance of fiber reinforced asphalt concrete at $-20^{\circ} \mathrm{C}$, Constr. Build. Mater. 81 (2015) 47-57. doi:10.1016/j.conbuildmat.2015.02.005.

[148] K. Anurag, F. Xiao, S.N. Amirkhanian, Laboratory investigation of indirect tensile strength using roofing polyester waste fibers in hot mix asphalt, Constr. Build. Mater. 23 (2009) 2035-2040. doi:10.1016/j.conbuildmat.2008.08.018.

[149] T. Takaikaew, P. Tepsriha, S. Horpibulsuk, M. Hoy, K.E. Kaloush, A. Arulrajah, Performance of Fiber-Reinforced Asphalt Concretes with Various Asphalt Binders in Thailand, J. Mater. Civ. Eng. 30 (2018) 04018193. doi:10.1061/(ASCE)MT.1943-5533.0002433. 